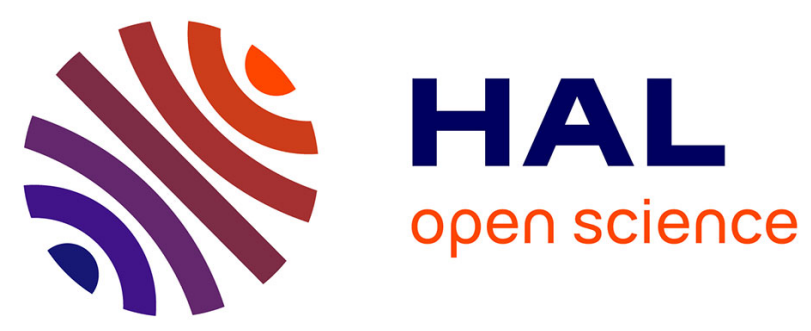

\title{
The Hadley and Walker Circulation Changes in Global Warming Conditions Described by Idealized Atmospheric Simulations
}

\author{
Guillaume Gastineau, Laurent Li, Hervé Le Treut
}

\section{- To cite this version:}

Guillaume Gastineau, Laurent Li, Hervé Le Treut. The Hadley and Walker Circulation Changes in Global Warming Conditions Described by Idealized Atmospheric Simulations. Journal of Climate, 2009, 22 (14), pp.3993-4013. 10.1175/2009JCLI2794.1 . hal-01332190

\section{HAL Id: hal-01332190 \\ https://hal.sorbonne-universite.fr/hal-01332190}

Submitted on 15 Jun 2016

HAL is a multi-disciplinary open access archive for the deposit and dissemination of scientific research documents, whether they are published or not. The documents may come from teaching and research institutions in France or abroad, or from public or private research centers.
L'archive ouverte pluridisciplinaire HAL, est destinée au dépôt et à la diffusion de documents scientifiques de niveau recherche, publiés ou non, émanant des établissements d'enseignement et de recherche français ou étrangers, des laboratoires publics ou privés. 


\title{
The Hadley and Walker Circulation Changes in Global Warming Conditions Described by Idealized Atmospheric Simulations
}

\author{
Guillaume GASTINEAU \\ Laboratoire de Météorologie Dynamique, CNRS, Université Pierre et Marie Curie, Paris, France, and Rosenstiel School \\ for Marine and Atmospheric Science, University of Miami, Miami, Florida \\ LAURENT Li AND HeRvé LE TREuT \\ Laboratoire de Météorologie Dynamique, CNRS, Université Pierre et Marie Curie, Paris, France
}

(Manuscript received 15 August 2008, in final form 9 January 2009)

\begin{abstract}
Sea surface temperature (SST) changes constitute a major indicator and driver of climate changes induced by greenhouse gas increases. The objective of the present study is to investigate the role played by the detailed structure of the SST change on the large-scale atmospheric circulation and the distribution of precipitation. For that purpose, simulations from the Institut Pierre-Simon Laplace Coupled Model, version 4 (IPSL-CM4) are used where the carbon dioxide $\left(\mathrm{CO}_{2}\right)$ concentration is doubled. The response of IPSL-CM4 is characterized by the same robust mechanisms affecting the other coupled models in global warming simulations, that is, an increase of the hydrological cycle accompanied by a global weakening of the largescale circulation. First, purely atmospheric simulations are performed to mimic the results of the coupled model. Then, specific simulations are set up to further study the underlying atmospheric mechanisms. These simulations use different prescribed SST anomalies, which correspond to a linear decomposition of the IPSLCM4 SST changes in global, longitudinal, and latitudinal components. The simulation using a globally uniform increase of the SST is able to reproduce the modifications in the intensity of the hydrological cycle or in the mean upward mass flux, which also characterize the double $\mathrm{CO}_{2}$ simulation with the coupled model. But it is necessary (and largely sufficient) to also take into account the zonal-mean meridional structure of the SST changes to represent correctly the changes in the Hadley circulation strength or the zonal-mean precipitation changes simulated by the coupled model, even if these meridional changes by themselves do not change the mean thermodynamical state of the tropical atmosphere. The longitudinal SST anomalies of IPSL-CM4 also have an impact on the precipitation and large-scale tropical circulation and tend to introduce different changes over the Pacific and Atlantic Oceans. The longitudinal SST changes are demonstrated to have a smaller but opposite effect from that of the meridional anomalies on the Hadley cell circulations. Results indicate that the uncertainties in the simulated meridional patterns of the SST warming may have major consequences on the assessment of the changes of the Hadley circulation and zonal-mean precipitation in future climate projections.
\end{abstract}

\section{Introduction}

The tropical climate is determined by the complex interactions between the large-scale atmospheric circulation, the solar and terrestrial radiative transfer, the boundary layer, clouds, and the atmospheric convection (Betts and Ridgway 1988). Among all of these compo-

Corresponding author address: Guillaume Gastineau, Laboratoire de Météorologie Dynamique, Université Pierre et Marie Curie, 4 place Jussieu, 75005 Paris, France.

E-mail: gglmd@lmd.jussieu.fr nents, the role of the large-scale circulation and its coupling with the other processes must not be neglected, as it may explain some important regional changes expected from anthropogenic greenhouse gas emissions. Preceding studies have reported that the tropical circulation weakens in global warming projections using coupled GCMs. Betts and Ridgway (1989) and Betts (1998) demonstrated that the weakening of the tropical large-scale circulation has important consequences for the hydrologic cycle; these results were confirmed by the more recent study of Held and Soden (2006). Less water vapor is transported vertically from 
the atmospheric boundary layer to the free troposphere. Therefore, the weakening of the large-scale tropical circulation explains why the global increase of the hydrological cycle is, in the Fourth Assessment Report (AR4) coupled models, on the order of $2 \% \mathrm{~K}^{-1}$ of surface warming, whereas the Clausius-Clapeyron scaling imposes that the atmospheric water vapor increases at the larger rate of about $7 \% \mathrm{~K}^{-1}$.

The weakening of the large-scale circulation is consistent with the fact that the static stability increases more rapidly than the radiative cooling of the atmosphere in the subtropical regions, where air subsides (Knutson and Manabe 1995; Sugi et al. 2002).

It is convenient to decompose the large-scale tropical circulation by separating out the Hadley and Walker circulations. The Hadley circulation is the mean meridional overturning circulation, whereas the Walker circulation is the longitudinal overturning circulation, which is especially affected by the El Niño-Southern Oscillation (ENSO) over the Pacific Ocean. The Hadley and Walker circulations tend to respond differently to global warming conditions. Held and Soden (2006) and Vecchi and Soden (2007) showed that the decrease of the zonalmean component of the midtropospheric vertical velocity changes is proportionally weaker than the decrease of the mean vertical motion over the tropics. Similarly, Gastineau et al. (2008) found that the Hadley circulation is characterized by a modest decrease of about $4 \%$ in most AR4 coupled models in double $\mathrm{CO}_{2}$ conditions. On the other hand, Vecchi and Soden (2007), using ascending midtropospheric velocity at the $500-\mathrm{hPa}$ height, estimate the weakening of the global circulation as approximately $5 \%-10 \% \mathrm{~K}^{-1}$ of surface warming, suggesting that the global weakening of the circulations is lesser for the Hadley circulation, which is still poorly explained. The changes of the Walker circulation were attributed by recent studies to the global increase of the atmospheric stability and to changes in the equatorial sea surface temperature (SST) gradient over the Pacific Ocean (Held and Soden 2006; Vecchi and Soden 2007).

Furthermore, recent studies diagnosed a poleward expansion of the Hadley cells in the AR4 coupled model simulations ( $\mathrm{Lu}$ et al. 2007). This poleward expansion was shown to be associated with a poleward displacement of the dry zones in most coupled model simulations of global warming conditions. Some satellite observations confirm these results, as a poleward displacement of the outgoing longwave radiation (OLR) was diagnosed in the High Resolution Infrared Sounder (HIRS) over the period 1979-2004 ( $\mathrm{Hu}$ and $\mathrm{Fu}$ 2007). The mechanism explaining this poleward displacement of the Hadley cells is still unclear. It may result from different mechanisms acting together. Lu et al. (2008) suggested that three key parameters could explain this poleward shift: the rise of the tropopause under global warming, changes in the properties of midlatitude eddies, and changes in the poleward atmospheric energy transport.

The aim of this paper is to investigate some of the mechanisms that may explain the asymmetry of the changes between the Walker and the Hadley circulation, the changes of the hydrological cycle, and the poleward expansion of the Hadley cells. We investigate these processes by analyzing the response of an atmospheric GCM to a set of idealized SST changes deduced from the results of a single coupled model, The Institut Pierre-Simon Laplace Coupled Model, version 4 (IPSL-CM4). In section 2, we first describe our methodology and show how we set up ensemble atmospheric simulations using prescribed SSTs from IPSL-CM4 that are able to mimic the results of this same coupled model in terms of dry static stability and precipitation changes. Then, idealized experiments are designed to separate out the response of the coupled model into the global, meridional, and longitudinal components of the prescribed SST changes. In section 3, our results are discussed to investigate the mechanisms that lead to different Hadley and Walker circulation changes together with the changes of the precipitation patterns. Discussion and conclusions are given in section 4 .

\section{General methodology}

\section{a. Presentation of the IPSL-CM4 coupled model simulations}

First, outputs of a double $\mathrm{CO}_{2}$ simulation using the IPSL-CM4 coupled model are studied. (These outputs are available online at http://mc2.ipsl.jussieu.fr/ simules.html.) We specifically study the results of two simulations that follow the experimental protocol defined by the Coupled Model Intercomparison Project phase 3 (CMIP3) and include respectively (i) a stabilized period of $30 \mathrm{yr}$ when all greenhouse gases are set to preindustrial concentrations and (ii) a simulated period of $30 \mathrm{yr}$ following successively an idealized $1 \%$ yearly increase of the $\mathrm{CO}_{2}$ concentration and a 200-yr stabilization at the double $\mathrm{CO}_{2}$ concentration (with reference to the preindustrial level). The first simulation is used as a control simulation and is denoted $\mathrm{C} \mathrm{CO}_{2}$, whereas the second simulation constitutes a stable simulation in global warming conditions and is denoted $\mathrm{C}_{2} \mathrm{CO}_{2}$.

The reader is referred to Table 1 for a summary of the atmospheric and coupled simulations used in the study. 
TABLE 1. Description of the simulations: The first two simulations are coupled simulations using the coupled model, IPSL-CM4; the other simulations are atmosphere-only with different prescribed SST and sea ice extension (SIC) using the LMDZ4 atmospheric GCM. The time interval is 30 years in all simulations.

\begin{tabular}{llcl}
\hline \hline Simulation & \multicolumn{1}{c}{ SIC } & $\mathrm{CO}_{2}(\mathrm{ppm})$ & \multicolumn{1}{c}{ SST } \\
\hline $\mathrm{C} 1 \mathrm{CO} 2$ & Coupled & 286.20 & Coupled \\
$\mathrm{C} 2 \mathrm{CO} 2$ & Coupled & 574.34 & Coupled \\
$1 \mathrm{CO} 2$ & From $\mathrm{C} 1 \mathrm{CO}_{2}$ & 286.20 & From $\mathrm{C}^{2} \mathrm{CO}_{2}$ \\
$2 \mathrm{CO} 2$ & From $\mathrm{C}_{2} \mathrm{CO}_{2}$ & 574.34 & From $\mathrm{C}_{2} \mathrm{CO}_{2}$ \\
$\Delta \mathrm{SST}$ & From $\mathrm{C} 1 \mathrm{CO}_{2}$ & 286.20 & From $\mathrm{C}_{2}$ \\
$\mathrm{GM}$ & From $\mathrm{ClCO}_{2}$ & 286.20 & Change in the global mean \\
$\mathrm{MS}$ & From $\mathrm{C}_{2} \mathrm{CO}_{2}$ & 286.20 & Change in the meridional structure \\
$\mathrm{LS}$ & From $\mathrm{C}_{1} \mathrm{CO}_{2}$ & 286.20 & Change in the longitudinal structure \\
\hline
\end{tabular}

\section{b. Presentation of the control atmospheric simulations}

The Laboratoire de Météorologie Dynamique (LMD) version 4 atmospheric GCM, LMDZ4 (the Z standing for the zoom capacity) is run in response to prescribed SST from the coupled model IPSL-CM4 to test the capacity of atmosphere-only simulations to mimic its results. The LMDZ4 atmospheric GCM is the atmospheric component of IPSL-CM4. Both IPSL-CM4 and the prescribed SST simulations are run with the same resolution, that is, $2.53^{\circ}$ latitude $\times 3.75^{\circ}$ longitude and 19 vertical levels. The reader is referred to Hourdin et al. (2006) for an extensive description of the parameterized physics of LMDZ4. An important characteristic of this model is the use of the Emanuel scheme (Emanuel 1993) for parameterized convection with a complex representation of entrainment and detrainment that interacts with cloud proprieties (Bony and Emanuel 2001). The surface-vegetation Organizing Carbon and Hydrology in Dynamic Ecosystems model (ORCHIDEE) (Krinner et al. 2005) is used in both the coupled and the atmosphere-only simulations.

Figure 1 shows the SST changes simulated in IPSL$\mathrm{CM} 4$ between $\mathrm{C}_{2} \mathrm{CO}_{2}$ and $\mathrm{C}_{1} \mathrm{CO}_{2}$. The globally aver- aged surface temperature increase in $\mathrm{C}_{2} \mathrm{CO}_{2}$ is $+2.9 \mathrm{~K}$, which ranks IPSL-CM4 among the rather insensitive coupled models. Previous studies emphasized the main characteristics of these simulations. A weak warming over the northern Atlantic Ocean is associated with a strong slowdown of the thermohaline circulation (Swingedouw et al. 2006). The SSTs over the Southern Ocean warm less than in the other oceans owing to changes in wind forcing and deep-water formation (Russell et al. 2006). The mean meridional circulation change has also been compared to the other coupled models of the AR4 by Gastineau et al. (2008). The IPSL-CM4 coupled model is sufficiently generic to be used for further global warming studies.

In a first set of simulations, we use prescribed SST and sea ice extent from the IPSL-CM4 coupled model as boundary conditions for the LMDZ4 atmospheric GCM. Daily climatological SST and sea ice extent are computed from a 30-yr time series for both the $\mathrm{C}^{-\mathrm{CO}_{2}}$ and $\mathrm{C} 2 \mathrm{CO}_{2}$ simulations. Then, these climatological fields are used as boundary conditions for ensembles of 30 atmospheric 1-yr simulations. Each 1-yr ensemble member simulation is generated by a random sampling of the initial atmospheric conditions, following the methodology described in $\mathrm{Li}$ (2006). Practically, these simulations are performed by one 30-yr integration using stable
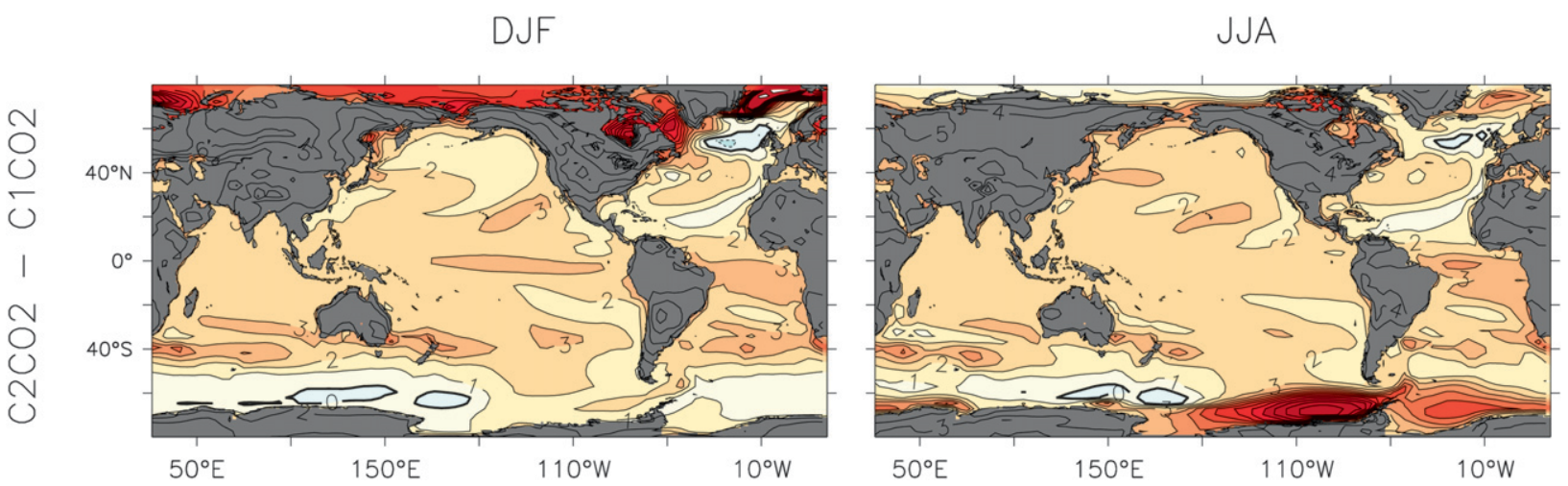

FIG. 1. Sea surface temperature $(\mathrm{K})$ difference between the double $\mathrm{CO}_{2}$ simulation $\left(\mathrm{C} 2 \mathrm{CO}_{2}\right)$ and the preindustrial control simulation $\left(\mathrm{ClCO}_{2}\right)$ of the coupled model, IPSL-CM4, for (left) boreal winter (DJF) and (right) austral winter (JJA). 


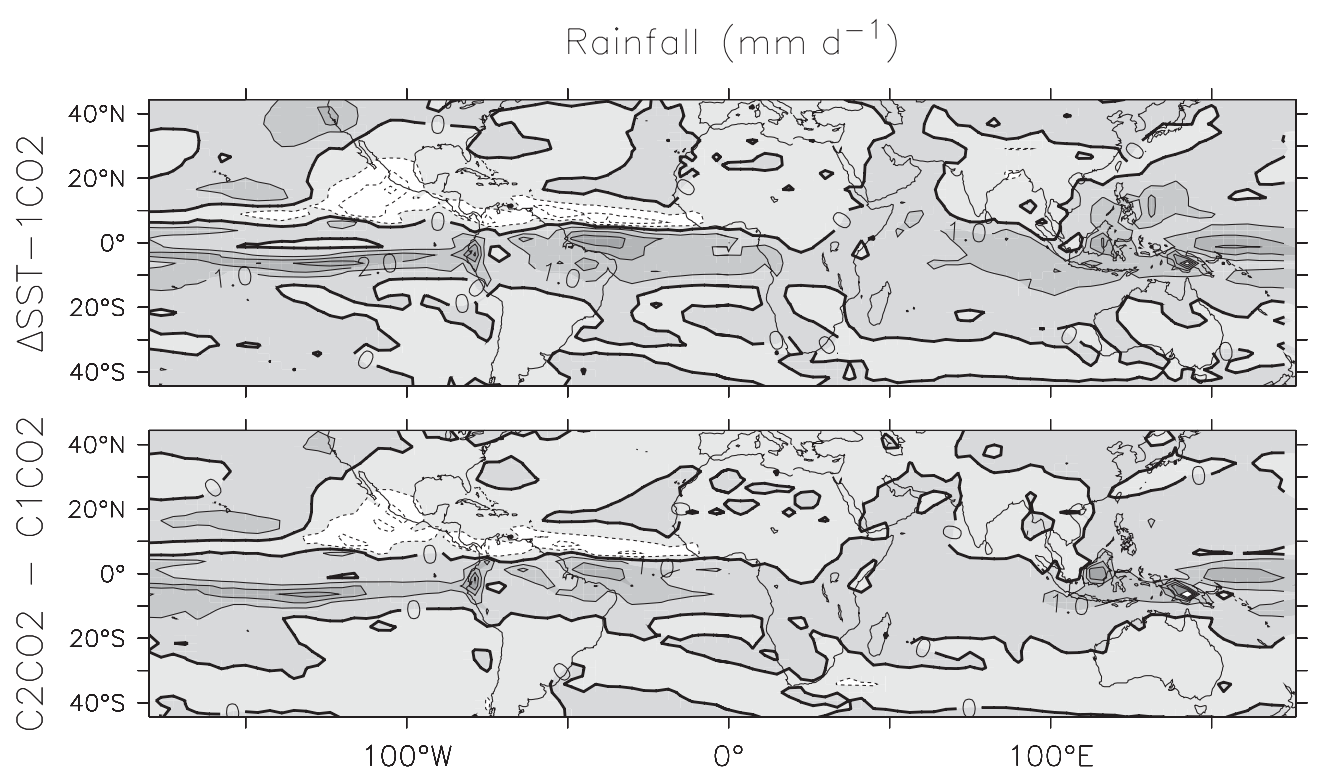

FIG. 2. Rainfall (mm day ${ }^{-1}$ ), in yearly mean, corresponding to (top) the differences of the SST-prescribed simulations $\triangle \mathrm{SST}$ and $1 \mathrm{CO} 2$ and (bottom) the differences of the IPSL-CM4 simulations $\mathrm{C} 2 \mathrm{CO} 2$ and $\mathrm{C} 1 \mathrm{CO} 2$.

initial conditions. Indeed, with prescribed SST the chaotic nature of the climate system explains that each year can be considered as a random sample when compared to the following and preceding years.

The two ensembles called $1 \mathrm{CO} 2$ and $2 \mathrm{CO} 2$ are carried out using the $\mathrm{CO}_{2}$ concentration, sea ice extent, and SST from respectively the coupled simulations $\mathrm{C}_{1} \mathrm{CO}_{2}$ and $\mathrm{C}_{2} \mathrm{CO}_{2}$. The differences between the coupled and atmosphere-only simulations remain very weak when averaged over the 30 one-year samples. The rms errors of the yearly average surface air temperature over nonoceanic grid points is only $0.52 \mathrm{~K}(0.15 \mathrm{~K})$ in midlatitudes (tropics). We note that, over polar regions, systematic warmer surface temperatures of 1.9 and $1.20 \mathrm{~K}$, on average, are found over sea ice and continent areas, respectively, when comparing the atmosphere-only simulation with the coupled ones. Over the sea-ice-covered areas differences can reach $4-5 \mathrm{~K}$ locally. Such differences result from the different sea ice parameterizations used in the atmospheric and coupled simulations. Overall, the simulations $1 \mathrm{CO} 2$ and $2 \mathrm{CO} 2$ are atmosphere only and are reasonably able to mimic the coupled model simulations, especially in the tropical latitudes.

\section{c. The effect of the SST changes}

To study the contribution of the SST changes only, we perform 30 one-year simulations, using the SST from $\mathrm{C}_{2} \mathrm{CO}_{2}$ while keeping the sea ice extent and the $\mathrm{CO}_{2}$ concentration of the $\mathrm{C}^{-\mathrm{CO}_{2}}$ configuration. As described in the preceding section, the simulations are generated by a random sampling of the initial atmospheric con- ditions. This ensemble of simulations is called $\Delta$ SST and captures the effects of the changes in SST associated with a double $\mathrm{CO}_{2}$ concentration without taking into account the direct radiative effect of the $\mathrm{CO}_{2}$ increase. The consequences of the sea ice melting are also not accounted for in $\triangle \mathrm{SST}$.

In $\mathrm{C}_{2} \mathrm{CO}_{2}$ and $2 \mathrm{CO} 2$, the $\mathrm{CO}_{2}$ doubling increases the atmospheric absorption and emission of longwave radiation and results in a net radiative heating of the atmospheric column. In $\Delta S S T$, a new surface energy balance is achieved as the $\mathrm{CO}_{2}$ atmospheric concentration is unchanged. In $\Delta$ SST the hydrological cycle increase compensates for the missing $\mathrm{CO}_{2}$ radiative heating, as it is commonly seen in such simulations (see review of Allen and Ingram 2002). The precipitation increases globally by about $0.05 \mathrm{~mm}_{\text {day }}{ }^{-1}$ when compared to the $2 \mathrm{CO} 2$ simulation, whereas the surface turbulent latent heat flux increases globally by $2 \mathrm{~W} \mathrm{~m}^{-2}$.

Figure 2 gives the precipitation differences between the atmospheric simulations $\triangle \mathrm{SST}$ and $1 \mathrm{CO} 2$ and between the coupled simulations $\mathrm{C} 2 \mathrm{CO} 2$ and $\mathrm{C} 1 \mathrm{CO} 2$. A southward shift of the ITCZ over the equatorial Atlantic and eastern Pacific Oceans is simulated by both atmospheric and coupled simulations. We also diagnose stronger precipitation over the warm pool region in both sets of simulations. The mean increase of the hydrologic cycle due to the missing radiative effect of the $2 \mathrm{CO} 2$ in $\triangle \mathrm{SST}$ is much smaller than the consequences of the SST increase. It is clear that, in the tropical region, the changes of the SST only are able to drive the main changes in the rainfall pattern. Therefore, the main 
mechanisms driving the changes in the hydrological cycle, involving large-scale tropical circulation changes, are expected to be similar when the atmospheric simulations $(\Delta \mathrm{SST}$ and $1 \mathrm{CO} 2)$ and the coupled reference runs $(\mathrm{C} 2 \mathrm{CO} 2$ and $\mathrm{C} 1 \mathrm{CO} 2)$ are compared.

Another crucial parameter affecting global warming in the tropical region is dry static stability. Dry static stability changes were demonstrated to govern the large-scale circulation weakening of the atmosphere (Knutson and Manabe 1995; Sugi et al. 2002). Figure 3 shows the changes of mean temperature profiles averaged over the tropical region, defined here as the region between $30^{\circ} \mathrm{N}$ and $30^{\circ} \mathrm{S}$. The slope of the mean temperature profile is roughly proportional to the dry static stability of the atmosphere. We could check that the dry static stability increases undergo similar modifications in atmospheric and coupled runs. The atmospheric convection occurring in the tropical regions constrains the value of the lapse rate and imposes that it stays close to the moist adiabat (Xu and Emanuel 1989). As the surface air temperature changes are equal in the tropics, these lapse rate changes are also very closely similar in both coupled and uncoupled simulations. Therefore, the differences between $\Delta \mathrm{SST}$ and $1 \mathrm{CO} 2$ are expected to represent fairly well the changes of the coupled model in terms of large-scale tropical changes.

\section{d. Prescribed SST simulations using idealized SST warming anomalies}

As the SST determined by ocean-atmosphere coupling is able to drive the large-scale tropical circulation changes, we use different patterns of SST warming and study the consequences for rainfall and the large-scale circulation. We examine separately the impact of uniform changes of the global SST, as well as meridional and longitudinal SST changes associated with a double $\mathrm{CO}_{2}$ level. In what follows, we perform atmospheric simulations that use the sea ice extent and the greenhouse gas concentration of the coupled model control simulation, $\mathrm{C}_{1} \mathrm{CO}_{2}$, but we add a specified spatial component of the SST change pattern from $\mathrm{ClCO}_{2}$.

First, a global-mean daily uniform SST warming is computed and is designated as $\Delta \mathrm{SST}_{\mathrm{GM}}$ :

$$
\Delta \operatorname{SST}_{\mathrm{GM}}=\int_{-\pi}^{\pi} \int_{0}^{2 \pi} \Delta \operatorname{SST}(\lambda, \phi) \cos \phi d \lambda d \phi .
$$

Here $\lambda$ and $\phi$ indicate the longitude and latitude, respectively, and $\Delta \operatorname{SST}(\lambda, \phi)$ is the SST warming of the coupled model IPSL-CM4 between the double $\mathrm{CO}_{2}$ $(\mathrm{C} 2 \mathrm{CO} 2)$ and preindustrial control $(\mathrm{C} 1 \mathrm{CO} 2)$ simulations.

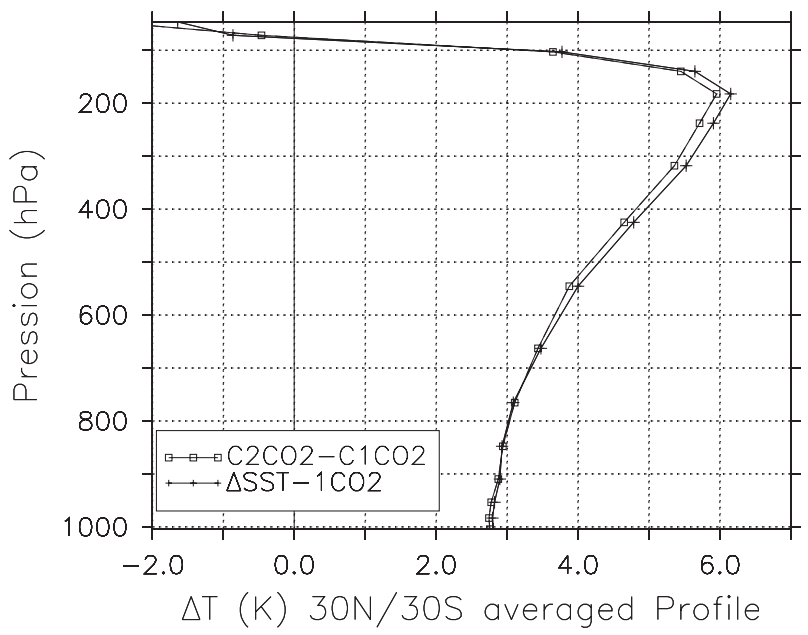

FIG. 3. Changes in the temperature $(\mathrm{K})$ profile: The differences of the atmospheric simulations $\triangle \mathrm{SST}$ and $1 \mathrm{CO} 2$ are compared with the differences of the IPSL-CM4 simulations $\mathrm{C} 2 \mathrm{CO} 2$ and $\mathrm{C} 1 \mathrm{CO} 2$. The results are from yearly averages.

Then, the meridional structure of the warming, or the changes of the meridional SST gradients, is obtained as the difference between the zonal-mean SST warming and the global mean warming:

$$
\Delta \operatorname{SST}_{\mathrm{MS}}(\phi)=\int_{0}^{2 \pi} \Delta \operatorname{SST}(\lambda, \phi) \cos \phi d \lambda-\Delta \operatorname{SST}_{\mathrm{GM}} .
$$

We designate the meridional structure of the SST warming by $\Delta \operatorname{SST}_{\mathrm{MS}}(\phi)$.

The longitudinal structure of the SST, or the changes in the longitudinal SST gradients, is computed as the mean residual once the global mean and the meridional structure of the SST are extracted:

$$
\Delta \operatorname{SST}_{\mathrm{LS}}(\lambda, \phi)=\Delta \operatorname{SST}(\lambda, \phi)-\Delta \operatorname{SST}_{\mathrm{GM}}-\Delta \operatorname{SST}_{\mathrm{MS}}(\phi) .
$$

We designate this mean longitudinal structure of the SST warming by $\Delta \operatorname{SST}_{\mathrm{LS}}(\lambda, \phi)$.

The different patterns of SST warming are added to the SST of the preindustrial control simulation $\mathrm{C} 1 \mathrm{CO} 2$ to obtain SST fields called $\operatorname{SST}_{\mathrm{GM}}(\lambda, \phi), \operatorname{SST}_{\mathrm{MS}}(\lambda, \phi)$, and $\operatorname{SST}_{\mathrm{LS}}(\lambda, \phi)$, which are used to perform three sets of idealized simulations, with 30 one-year members each. These sets of simulations are called global mean (GM), meridional structure (MS), and longitudinal structure (LS). Each ensemble member is obtained through a random sampling of the initial conditions. In the following, the results are a climatological average over the 30 members. In each ensemble, the variability among the different members is small compared to the changes induced by the SST changes. 

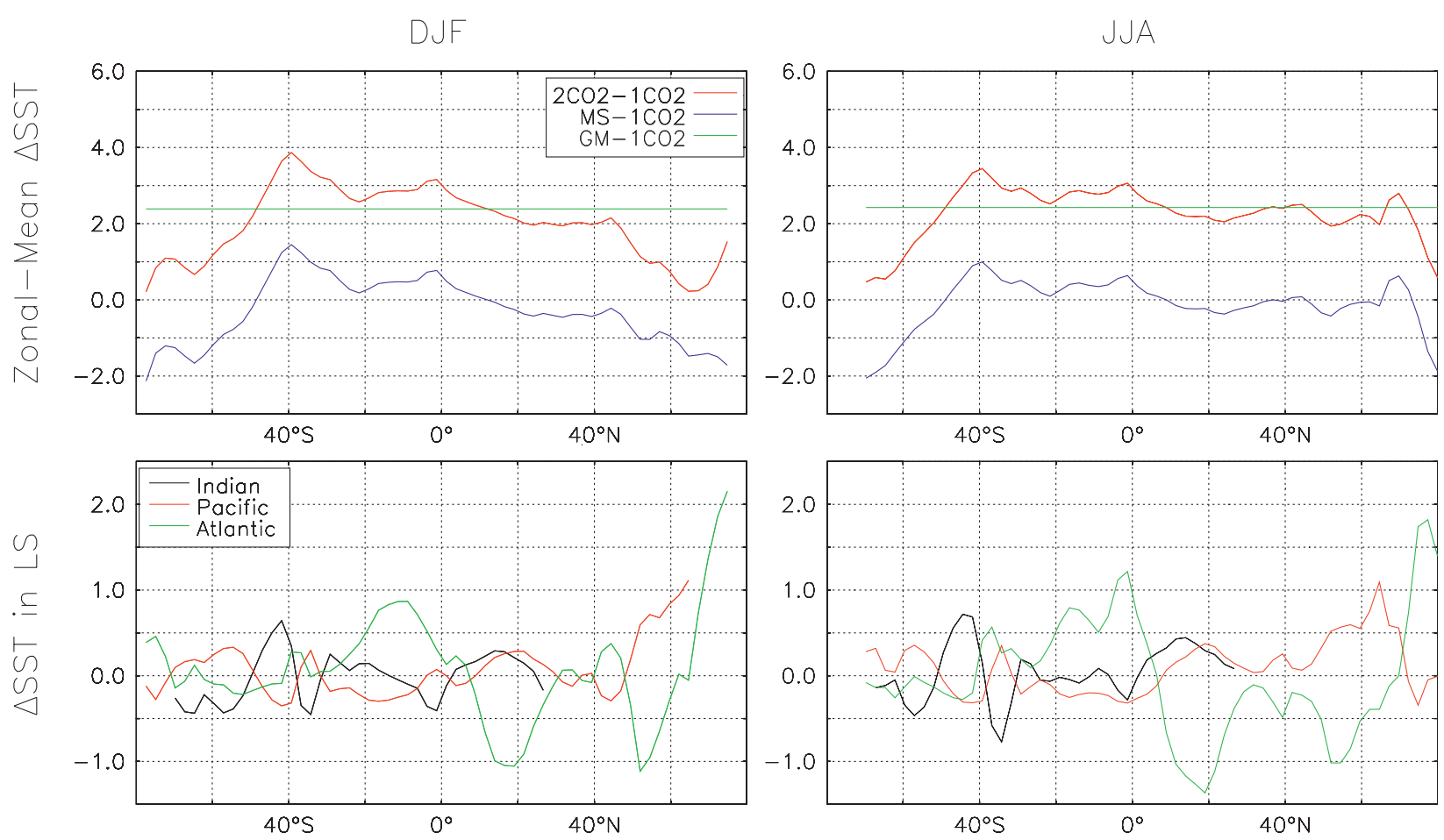

FIG. 4. SST anomalies (K) used as boundary conditions for the idealized simulations for (left) boreal winter (DJF) and (right) austral winter (JJA). (top) The zonal-mean SST anomalies for the simulations 2CO2, GM, and MS and (bottom) the SST anomalies of experiment LS, zonally averaged over three longitudinal bands shown in Fig. 5 that correspond to the Indian $\left(25^{\circ}-125^{\circ} \mathrm{E}\right)$, Atlantic $\left(70^{\circ} \mathrm{W}-25^{\circ} \mathrm{E}\right)$, and Pacific $\left(125^{\circ} \mathrm{E}-70^{\circ} \mathrm{W}\right)$ Oceans.

We note that with our definitions, the global mean change of the SST in the simulations MS and LS $\left(\Delta \mathrm{SST}_{\mathrm{MS}}\right.$ and $\Delta \mathrm{SST}_{\mathrm{LS}}$ ), when compared to the control, is zero, even if the meridional and longitudinal gradients of the SST are respectively modified. Furthermore, the SST changes of the simulations GM, MS, and LS correspond to a linear decomposition of the mean SST change associated with $\mathrm{CO}_{2}$ doubling: the sum of these three components corresponds to the full pattern of the SST change deduced from the coupled model IPSL-CM4:

$$
\Delta \operatorname{SST}(\lambda, \phi)=\Delta \operatorname{SST}_{\mathrm{GM}}+\Delta \operatorname{SST}_{\mathrm{MS}}(\phi)+\Delta \operatorname{SST}_{\mathrm{LS}}(\lambda, \phi) .
$$

To interpret the results of the simulations GM, MS, and LS in terms of potential mechanisms, a methodological issue needs to be raised. The attribution of the changes in the simulations GM, MS, and LS is possible only if this decomposition of the SST changes and their consequences are unique, for example, if it is not affected by any nonlinear effects. A simple test of this linearity is to verify that the sum of the changes of GM, MS, and LS is near enough to that of $\Delta$ SST. We therefore define a linearity parameter for any variable $x$ by the sum of the changes obtained in GM, MS, and LS:

$$
\Delta x_{\mathrm{GM}+\mathrm{MS}+\mathrm{LS}}=\Delta x_{\mathrm{GM}}+\Delta x_{\mathrm{MS}}+\Delta x_{\mathrm{LS}},
$$

where $\Delta x_{\mathrm{GM}+\mathrm{MS}+\mathrm{LS}}$ indicates the linear component of the changes, as accounted for by our idealized experiments; $\Delta x_{\mathrm{GM}}, \Delta x_{\mathrm{MS}}$, and $\Delta x_{\mathrm{LS}}$ represent differences between the $1 \mathrm{CO} 2$ and the GM, MS, and LS simulations, respectively. In the following sections, the sum of the main changes for each pattern of SST will be studied and demonstrated to be similar to that induced in $\triangle \mathrm{SST}$, as long as global or zonal-mean changes are the focus.

Figure 4 shows the zonal-mean SST warming used for the different simulations GM, MS, and LS, named respectively $\Delta \mathrm{SST}_{\mathrm{GM}}, \Delta \operatorname{SST}_{\mathrm{MS}}(\phi)$, and $\Delta \operatorname{SST}_{\mathrm{LS}}(\lambda, \phi)$, for the seasons of the Northern [December-February (DJF)] and Southern Hemisphere [June-August (JJA)] winters.

The mean SST warming of IPSL-CM4, in response to a double $\mathrm{CO}_{2}$ concentration, is about $+2.5 \mathrm{~K}$ for both DJF and JJA. The meridional structure of the SST change may be surprising as it reveals a stronger warming over the tropics than over midlatitudes. This pattern is opposite to what is expected from the polar amplification of global warming, which accounts for a stronger warming at higher latitudes (Moritz et al. 2002). It is explained by the fact that polar amplification 
DJF
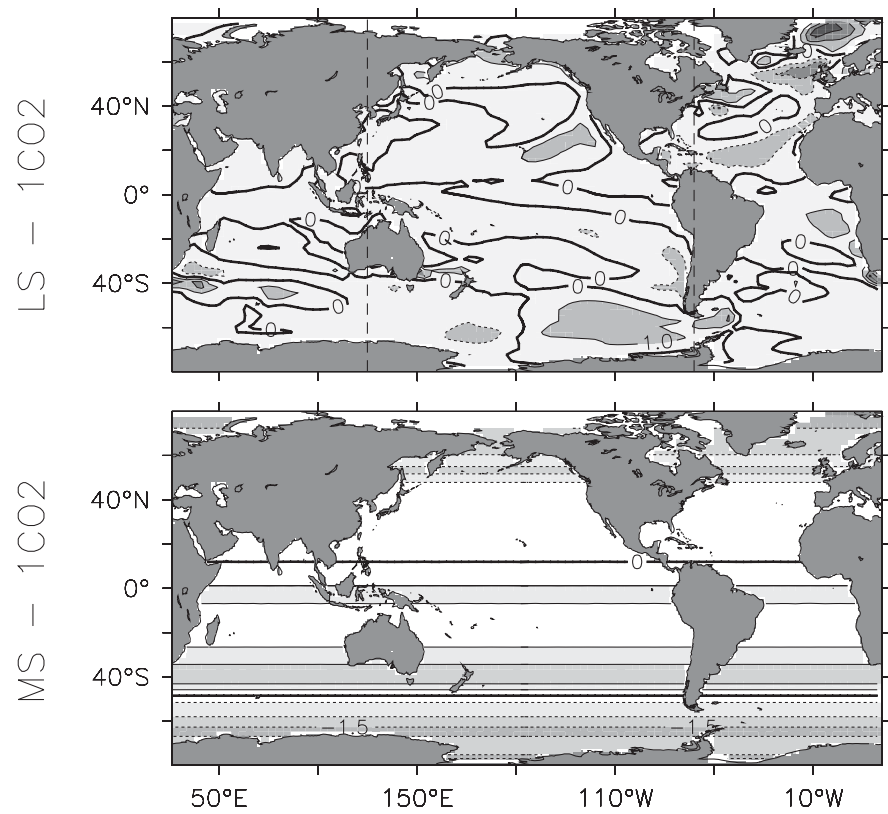
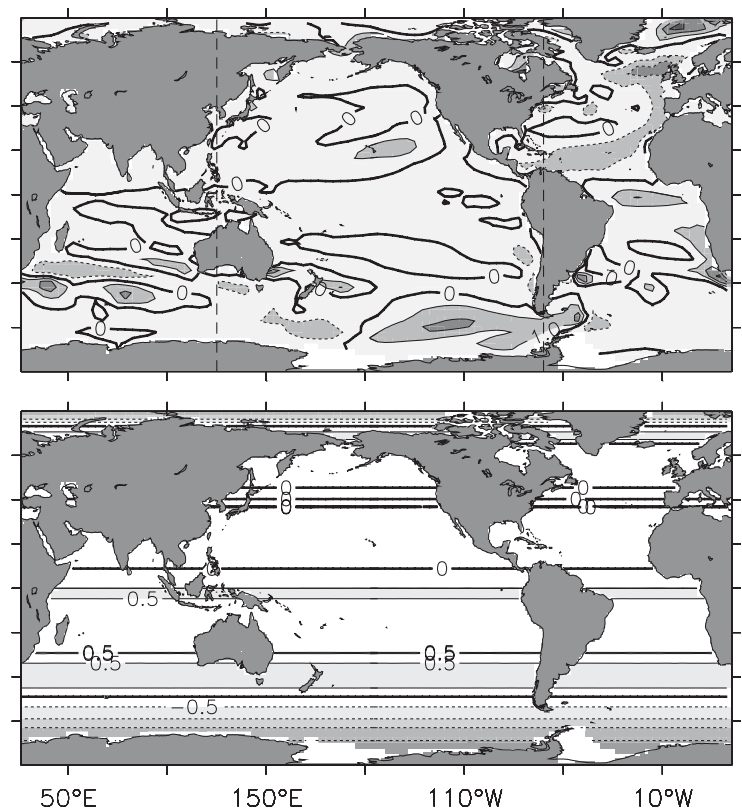

FIG. 5. SST used as boundary condition for the idealized simulations, shown as differences with the $1 \mathrm{CO} 2$ control simulation, that is, LS-1CO2 and MS-1CO2, for (left) boreal winter (DJF) and (right) austral winter (JJA). The boundaries of the three longitudinal bands used in Figs. 4, 14, and 15 are shown with dashed lines in the top panel. Contour intervals are (top) $1 \mathrm{~K}$ and (bottom) $0.5 \mathrm{~K}$.

mainly occurs over land and sea ice surfaces in our simulations (not shown).

If we examine the tropical latitudes, the warming is strongly asymmetric. Between $40^{\circ} \mathrm{N}$ and $40^{\circ} \mathrm{S}$ we note a stronger warming in the Southern Hemisphere than in the Northern Hemisphere, especially for DJF. Two warming maxima occur at $40^{\circ} \mathrm{S}$ and around the equator. The equatorial maximum warming is consistent with the other coupled models as shown by Liu et al. (2005). We can anticipate that the DJF Northern Hemisphere Hadley cell may intensify owing to the stronger zonal-mean meridional SST gradient between $40^{\circ} \mathrm{N}$ and $0^{\circ}$ and that the JJA Hadley cell may decrease owing to the weaker meridional SST gradient between $40^{\circ} \mathrm{S}$ and $0^{\circ}$.

In LS, the zonal-mean meridional SST gradient is unchanged, but over the different oceanic basins some meridional SST changes are diagnosed locally. The changes of SST are mainly opposite when we compare the Atlantic Ocean to both the Pacific and Indian Oceans. In the Atlantic Ocean, we note a warming over the Southern Hemisphere tropical region $\left(0^{\circ}-30^{\circ} \mathrm{S}\right)$ and a cooling over that of the Northern Hemisphere $\left(0^{\circ}-\right.$ $\left.30^{\circ} \mathrm{N}\right)$. In the midlatitudes, the changes between $30^{\circ}$ and $50^{\circ} \mathrm{S}$ are more complex and correspond more to local effects. Therefore, over the winter hemisphere, the meridional SST gradient over the Atlantic Ocean increases between $30^{\circ}$ and $0^{\circ}$ for DJF and decreases for JJA. On the other hand, over the Pacific and Indian Oceans the changes are weaker and opposite with a weakly reduced (increased) meridional SST gradient for DJF (JJA). Thus, we can anticipate different changes of the meridional circulation over the Atlantic, Indian, and Pacific Oceans. These different SST meridional gradients may also have important implications for the Walker circulation.

Figure 5 shows a map of the prescribed SST anomalies used for the LS and MS simulations. MS shows the same structure as shown in Fig. 4. It is zonally symmetric by definition. In LS some strong local warm spots appear in the Indian Ocean at $45^{\circ} \mathrm{S}$ and in the Pacific sector of the Southern Ocean. On the other hand, some local cool spots occur in the northern Atlantic Ocean. The minimum warming over the northern Atlantic Ocean is related to the slowdown of the thermohaline circulation in IPSL-CM4, as studied by Swingedouw et al. (2006). In the tropics, the longitudinal structure reveals a strong asymmetry between the Pacific and Atlantic Oceans. In the Northern Hemisphere the subtropical Atlantic cools and the subtropical Pacific warms, while in the Southern Hemisphere the subtropical Atlantic warms and the subtropical Pacific cools.

\section{Large-scale circulation changes and relation with precipitation in the idealized experiments}

This section is dedicated to the study of the atmospheric response to the prescribed SST patterns through a number of key diagnostics. 

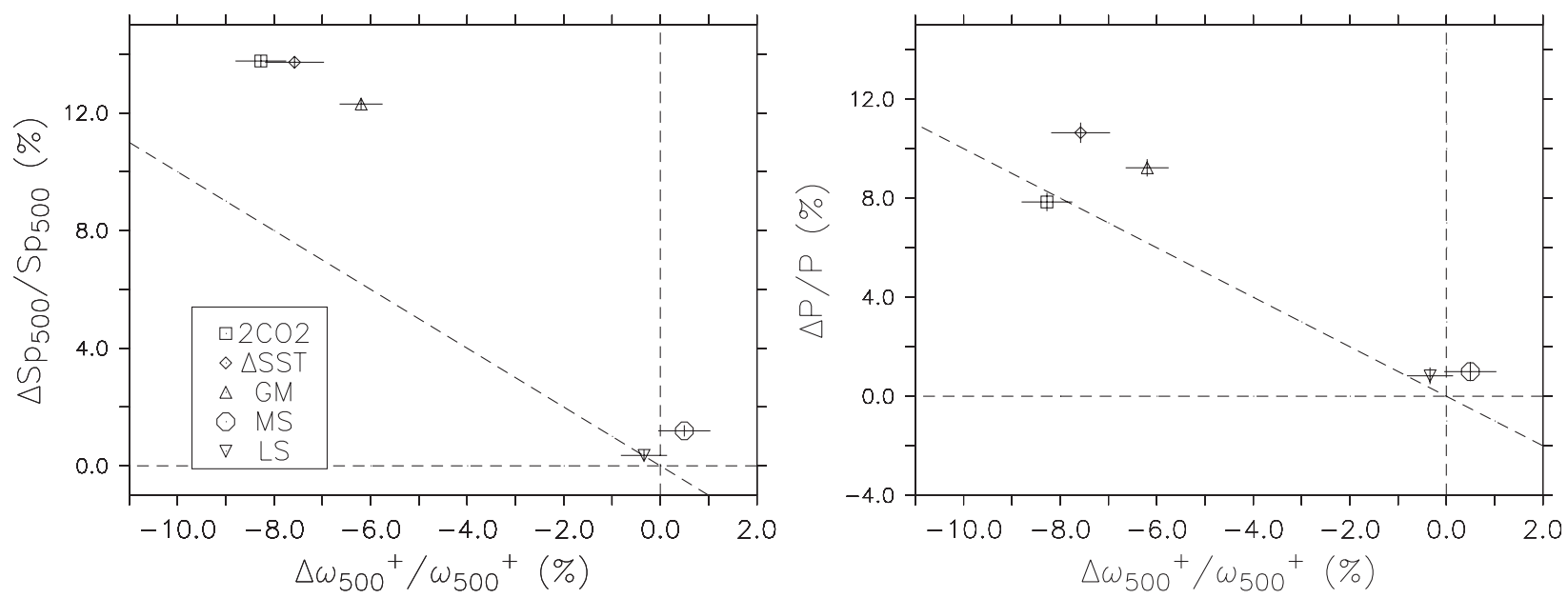

FIG. 6. Relative changes, averaged over the tropical region, in the mean midtropospheric vertical ascending pressure velocity, $\omega_{500}^{+}$ ( $x$ axis), vs (left) the relative changes in the mean static stability, $S_{p}$ ( $y$ axis), and (right) relative changes in the precipitation, $P(y$ axis), in the idealized simulations. The changes are given in percent and are averaged between $30^{\circ} \mathrm{N}$ and $30^{\circ} \mathrm{S}$. Vertical and horizontal lines represent the standard deviation among the 30 ensemble members for each variable.

\section{a. Midtropospheric vertical velocity}

The weakening of the large-scale atmospheric circulation in many climate change experiments has been identified as associated with a dry static stability increase in the atmosphere, induced by the global increase of the surface temperatures, especially in the tropics (Knutson and Manabe 1995; Sugi et al. 2002). Furthermore, recent studies using idealized simulations emphasized that the dry static stability increase in subtropics is especially crucial for the poleward expansion of the Hadley cells (Frierson et al. 2007; Walker and Schneider 2006; Korty and Schneider 2008).

Therefore, to study the impact of the SST changes on the large-scale circulation, the dry static stability has been computed with the static stability parameter $S_{p}$, defined as

$$
S_{p}=\frac{\partial T}{\partial p}-\frac{R T}{C_{p} p}=-\frac{T}{\theta} \frac{\partial \theta}{\partial p}
$$

where $T$ is the temperature, $p$ is the pressure, $R$ is the gas constant, $C_{p}$ is the specific heat at constant pressure, and $\theta$ is the potential temperature: $S_{p}$ is proportional to the buoyancy frequency of dry air.

Furthermore, the monthly mean upward pressure velocity at $500 \mathrm{hPa}, \omega_{500}^{+}$, is used as a measure of the atmospheric circulation in the different experiments, as described in Vecchi and Soden (2007). The left panel of Fig. 6 shows the tropical-mean upward midtropospheric pressure velocity changes at the $500-\mathrm{hPa}$ level, $\omega_{500}^{+}$, for the different idealized simulations ( $y$ axis) plotted against the mean tropical dry static stability changes $S_{p}$ ( $x$ axis). Both $\omega_{500}^{+}$and $S_{p}$ are averaged over the tropical region between $30^{\circ} \mathrm{N}$ and $30^{\circ} \mathrm{S}$. A weakening of the tropical circulation is well diagnosed for the simulations $2 \mathrm{CO} 2$ and $\Delta \mathrm{SST}$, as expected. This weakening of the tropical mean upward mass flux is about $-8 \%$ in $2 \mathrm{CO} 2$ and is of the same order as what has been diagnosed in the other AR4 models by Vecchi and Soden (2007). 2CO2 and $\Delta$ SST both show a strong increase in atmospheric dry static stability that slows down the atmospheric circulation.

In the simulation of uniform SST warming, GM, the tropical SST warming is less than for the coupled model because the SST warming is larger in the tropical region compared to the polar or midlatitude regions. As a consequence, the dry static stability increases less in GM than in $\triangle$ SST and the decrease of the global-mean upward midtropospheric vertical velocity is somewhat weaker in GM than in $\triangle$ SST. The other simulations, MS and LS, are only characterized by weak tropical SST anomalies, and the mean tropical warming for these simulations is small. Therefore, the tropical dry static stability changes and the global weakening of the tropical atmospheric circulation are also small in these simulations. We note that the use of the dry static stability averaged over the subtropical regions, defined between the $20^{\circ}$ and $40^{\circ}$ latitudes, does not significantly change the results of Fig. 6.

The precipitation changes are linked to the global increase of the surface temperature. Since the relative humidity in the troposphere is nearly constant in the simulations of global warming, the tropospheric water vapor content follows the Clausius-Clapeyron scaling and increases at a rate of $7 \% \mathrm{~K}^{-1}$. However, as the large-scale circulation slows down, coupled models 
simulate a somewhat weaker increase of the mean rainfall than the Clausius-Clapeyron scaling (Held and Soden 2006). In the right panel of Fig. 6, the increase of the rainfall is represented on the $y$ axis. In $2 \mathrm{CO} 2$, the mean increase of rainfall is less than in $\Delta$ SST as the radiative effect of $\mathrm{CO}_{2}$ decreases the mean rainfall in the tropical region. As shown in Fig. 2, the results of $\Delta$ SST and $2 \mathrm{CO} 2$ are still fairly similar despite these differences. The simulation of uniform warming, GM, is also characterized by a strong increase of the hydrological cycle. In GM, the increase of precipitation is weaker than that of $\Delta \mathrm{SST}$ as the mean uniform SST increase is weaker than the SST increase in the tropical region where the largest rainfall occurs. Finally, MS and LS only show insignificant mean precipitation changes.

\section{b. Large-scale atmospheric circulation}

In this section, we use the velocity potential at the 200-hPa level to diagnose the location of the large-scale atmospheric circulation changes. We follow the methodology detailed in Tanaka et al. (2004). The velocity potential at the $200-\mathrm{hPa}$ level, $\chi_{200}$, quantifies the mathematical circulation, that is, a line integral of tangential wind speed along a closed circle. The velocity potential reflects the large-scale features of the tropical circulation and is calculated using the horizontal wind at the 200-hPa level, following the definition

$$
\nabla \cdot \mathbf{v}=-\nabla^{2} \chi .
$$

Figure 7 shows the velocity potential at the $200-\mathrm{hPa}$ level, and the divergent wind vectors, for the control simulation $1 \mathrm{CO} 2$ and the changes of the velocity potential for the idealized experiment $\Delta$ SST, GM, MS, and LS, when compared to $1 \mathrm{CO} 2$. The rainfall pattern is added in color shades to emphasize the links between precipitation and large-scale circulation. Negative value of the velocity potential indicates a large-scale divergence of mass in the upper troposphere and locates where most of the convective ascents and precipitation occurs. Oppositely, positive $\chi_{200}$ indicates large-scale upper-tropospheric convergence and conditions where convection is suppressed.

The precipitation changes of $\Delta$ SST are similar to the changes described by the coupled model IPSL-CM4 in Fig. 2. Rainfalls located within the ITCZ are more intense both in the coupled model simulation and in $\Delta$ SST, because the hydrological cycle increases in global warming conditions. On the other hand, over the Pacific warm pool region, the large-scale circulation indicated by the $200-\mathrm{hPa}$ velocity potential slows down.

The uniform SST warming simulation, GM, also shows a global increase of rainfall within the ITCZ, accompanied by a weakening of the atmospheric circulation. The large-scale circulation changes over Asia and the Pacific warm pool region are similar for $\Delta$ SST and GM, suggesting that the uniform changes of the SST are able to reproduce the changes over the warm pool region where the strongest convective motions occur. However, for JJA, the weakening is somewhat smaller in GM than in $\triangle$ SST.

The simulations MS and LS show changes very different from GM and $\triangle$ SST, both in terms of precipitation and velocity potential. For these two simulations, the rainfall changes are more associated with displacements of the ITCZ than with a global increase of rainfall rate. In MS, for DJF and JJA, the ITCZ shifts southward, while in LS the ITCZ shifts northward over the Pacific Ocean and southward over the Atlantic Ocean.

In $\Delta$ SST, important ascending motions also occur over Central America for JJA. The uniform SST warming alone, GM, is unable to account for them; we therefore expect MS and LS to represent part of the signal, which is actually the case.

\section{c. Hadley circulation}

To understand the large-scale circulation changes, a diagnostic framework was built to assess the global changes of the large-scale circulation in terms of Hadley and Walker circulation changes.

The zonal-mean meridional streamfunction $\psi$ is computed for each simulation using idealized SST changes and compared to the $1 \mathrm{CO} 2$ control simulation. The streamfunction was computed using the zonal-mean meridional wind and the surface pressure, as described in Waliser et al. (1999).

Figure 8 shows the mean meridional streamfunction for the control simulation $1 \mathrm{CO} 2$, and the changes diagnosed in the idealized simulations. With our conventions, the streamfunction corresponding to a clockwise circulation is positive, as in the Northern Hemisphere winter (DJF) cell, whereas the streamfunction corresponding to a counterclockwise circulation is negative, as in the Southern Hemisphere winter (JJA) cell. Thus, a strengthening of the Hadley cell corresponds to a positive value of the streamfunction change for DJF and a negative value for JJA.

The Hadley circulation difference between $\Delta$ SST and $1 \mathrm{CO} 2$ in Fig. 8 is similar to that simulated by IPSL-CM4 and reported in Gastineau et al. (2008). The Hadley circulation for JJA weakens, which is coherent with the ensemble mean of the AR4 models. On the other hand, the Hadley circulation is slightly stronger for DJF, which is not coherent with the AR4 multimodel ensemble mean. 
DJF
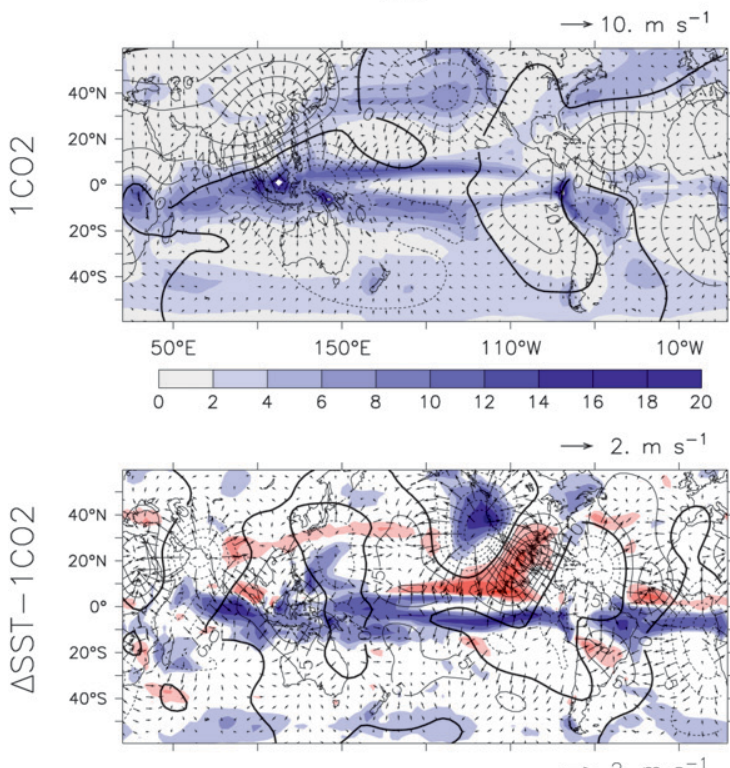

$\longrightarrow 2 . \mathrm{m} \mathrm{s}^{-1}$
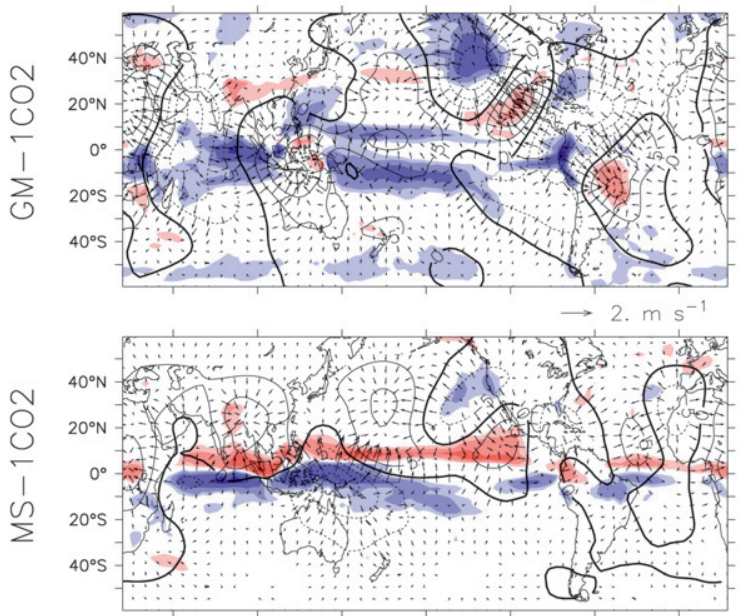

$\longrightarrow 2 \cdot \mathrm{m} \mathrm{s}^{-1}$

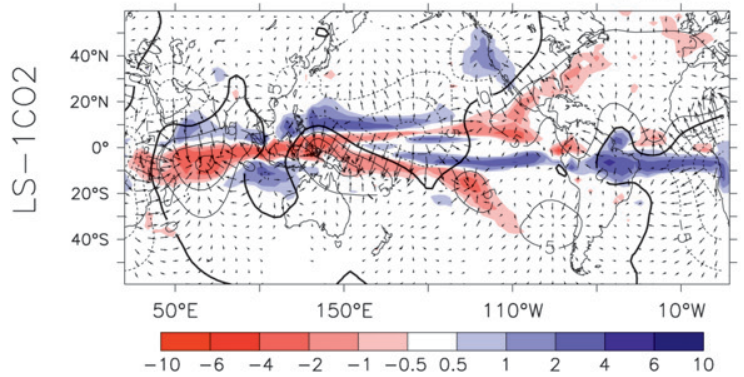

JJA

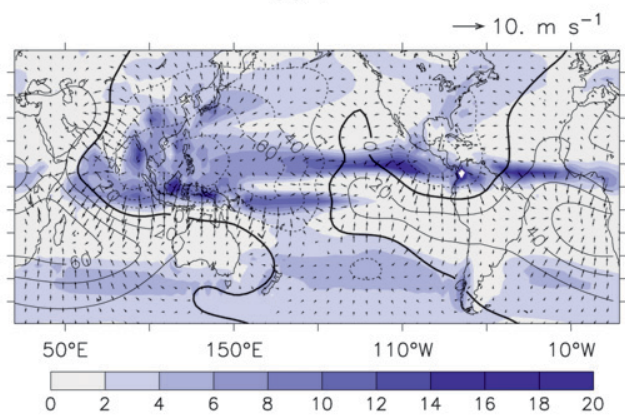

$\rightarrow 2 . \mathrm{m} \mathrm{s}^{-1}$

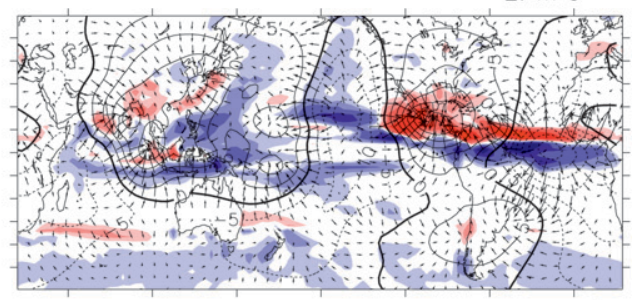

$\longrightarrow 2 \cdot \mathrm{m} \mathrm{s}^{-1}$

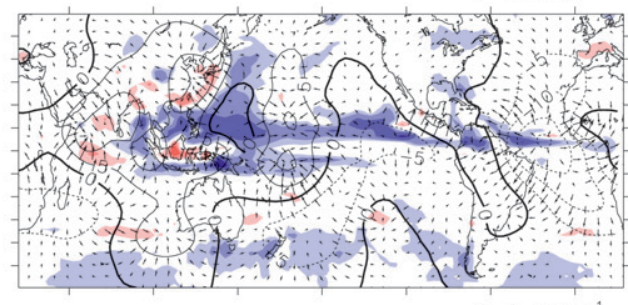

$\rightarrow 2 \mathrm{~ms}^{-1}$

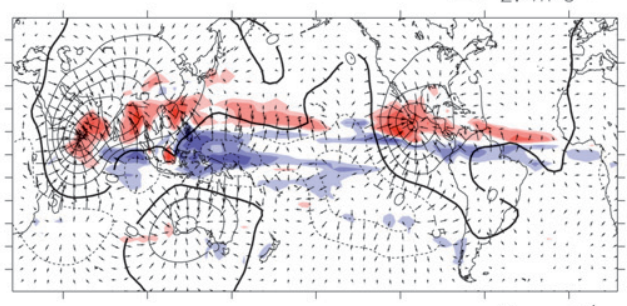

$\rightarrow 2 \cdot \mathrm{m} \mathrm{s}^{-1}$

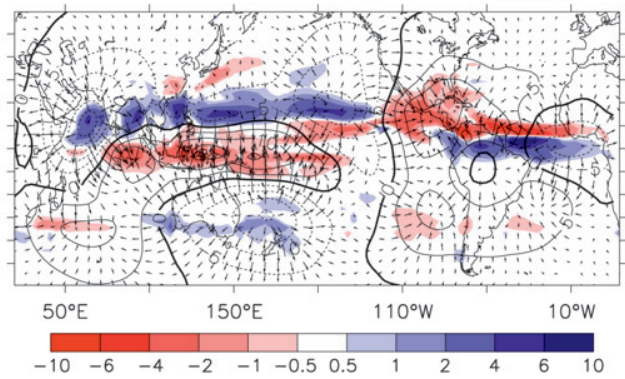

FIG. 7. Velocity potential at the 200-hPa height, $\chi_{200}$ in $10^{5} \mathrm{~m}^{2} \mathrm{~s}^{-1}$ (contours), and rainfall changes in mm day ${ }^{-1}$ (colors), for the different idealized simulations: (left) Northern Hemisphere winter (DJF) and (right) Southern Hemisphere winter (JJA). Vectors show the divergent wind speed and direction. Contour interval is $20 \times 10^{5} \mathrm{~m}^{2} \mathrm{~s}^{-1}$ in the top panel and $5 \times 10^{5} \mathrm{~m}^{2} \mathrm{~s}^{-1}$ in the lower panels. Colors show the rainfall pattern corresponding to the two color scales for the top and lower panels. 
DJF
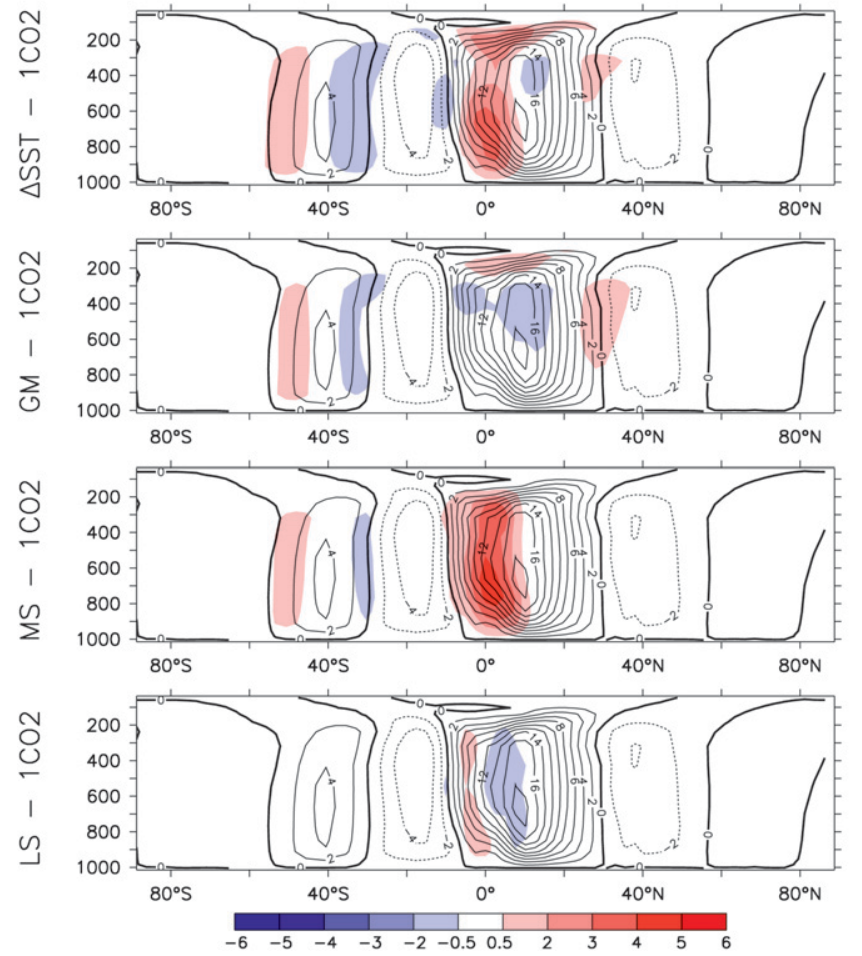

JJA
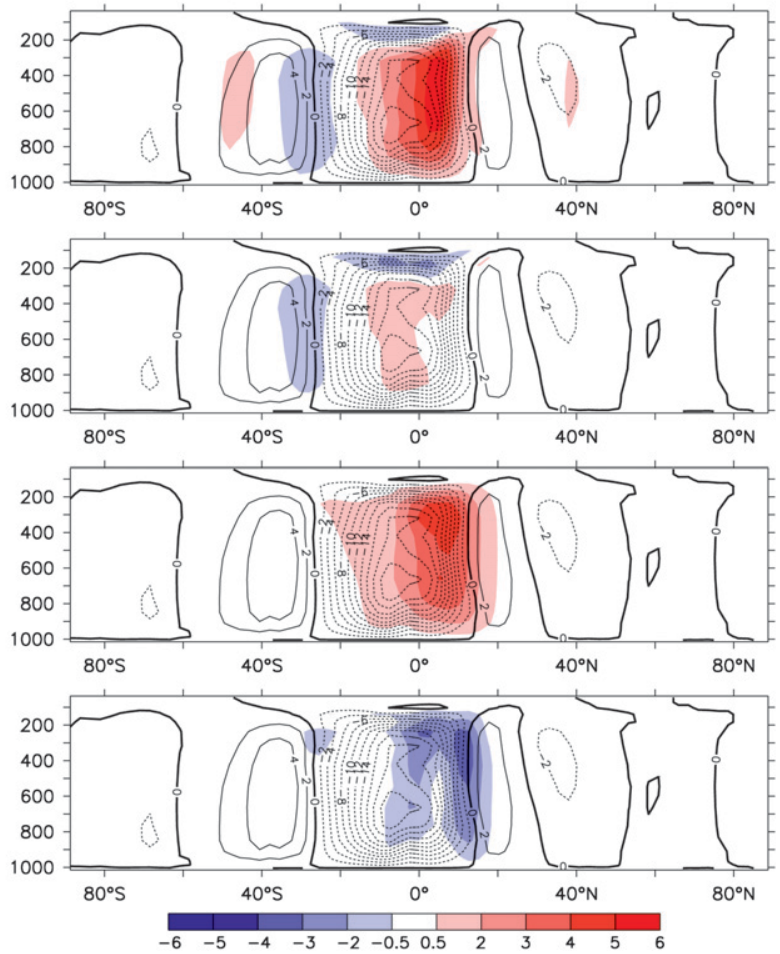

FIG. 8. Meridional zonal-mean streamfunction $\psi$ of the simulation $1 \mathrm{CO} 2$ (contours) and differences with $\Delta$ SST, GM, MS, and LS (colors) for (left) Northern Hemisphere winter (DJF) and (right) Southern Hemisphere winter (JJA). Units are $10^{10} \mathrm{~kg} \mathrm{~s}{ }^{-1}$. The color scales for DJF and JJA are identical; contour interval is $2 \times 10^{10} \mathrm{~kg} \mathrm{~s}^{-1}$.

The difference between GM and $1 \mathrm{CO} 2$ is characterized by a striking pattern that mimics only a few of the patterns simulated by the coupled model. The Hadley cells in the GM simulation gently weaken. The upward vertical displacement of the Hadley cells is reproduced, as seen by a positive (negative) anomaly in DJF (JJA) at $200 \mathrm{hPa}$, as the tropopause is displaced upward in the coupled models during global warming simulations (Santer et al. 2003).

On the contrary, the MS simulation shows a strong similarity with the $\Delta$ SST simulation, as the patterns are very similar except for the upward displacement in the upper levels of the winter Hadley cell. The tropopause height is not modified in the MS simulation, which reflects the fact that the tropical mean SST warming of MS is small. Nevertheless, the modifications of the SST gradient between the tropics and the midlatitudes tend to strengthen the DJF cell and weaken the JJA cell. This demonstrates that the Hadley cell intensification in the Northern Hemisphere winter, observed in the IPSL$\mathrm{CM} 4$ coupled simulation or $\Delta \mathrm{SST}$, is the consequence of the changes in the meridional SST gradients.

LS shows results that depend strongly on the season. A gentle weakening of the Hadley cell can be associated with SST longitudinal anomalies in DJF, whereas these SST longitudinal anomalies strengthen the JJA Hadley cell. Therefore, the longitudinal SST anomalies act in our simulations as a negative feedback onto the atmospheric circulation. The longitudinal anomalies have a weaker effect on the Hadley circulation than the actual SST changes of the coupled model, but this effect appears opposite in sign in all seasons.

To quantify the intensity of the winter Hadley cells and their extent in our different simulations, we follow the methodology described in Gastineau et al. (2008) and calculate (i) the maximum streamfunction absolute value, $\max (|\psi|)$, as a measure of the winter Hadley cell strength and (ii) the Hadley cell poleward expansion, defined using the diagnostic of Lu et al. (2007), that is, the precise latitude (obtained by linear interpolation) at which the average streamfunction takes the value 0.0 at the pressure level of $500 \mathrm{hPa}$. For both DJF and JJA, the streamfunction at $500 \mathrm{hPa}$ reaches the value 0.0 at three points between $45^{\circ} \mathrm{N}$ and $45^{\circ} \mathrm{S}$ : two at the extratropical edge of the Northern and Southern Hemisphere cells and one between the two cells. The latitude of the extratropical boundary of the Northern (Southern) Hemisphere Hadley cell during DJF (JJA) is used to 

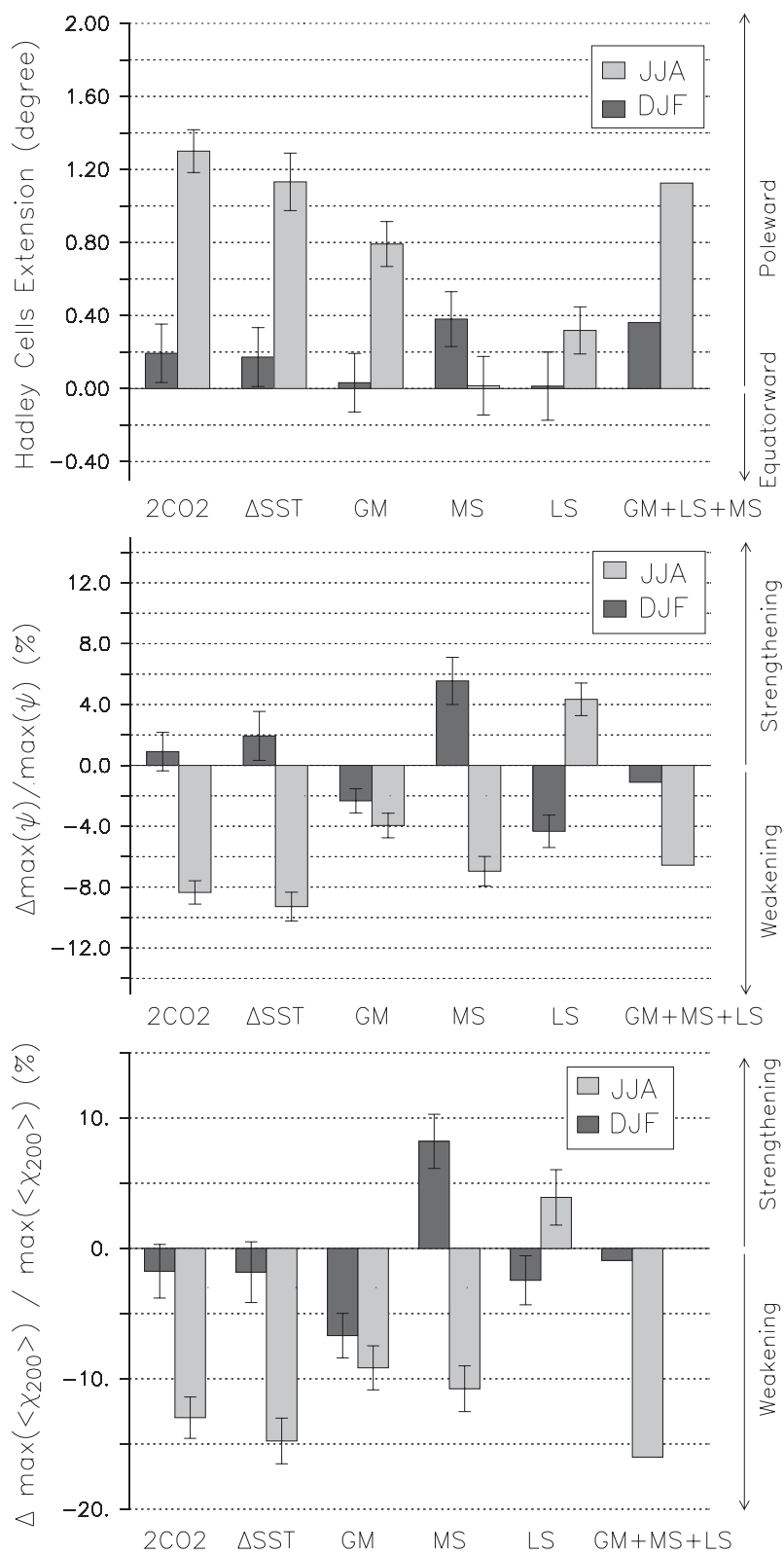

FIG. 9. (top) Winter Hadley cells expansion, in degrees of latitude; (middle) relative changes in the winter Hadley cell strength, indicated by the maximum absolute value of the zonal-mean meridional streamfunction $\max (|\psi|)$, in percent; and (bottom) relative changes of the Hadley circulation indicated by the zonal-mean velocity potential maximum. Errors bars indicate the $95 \%$ confidence level intervals using $t$ statistics, assuming that each 1-yr ensemble member is normally distributed; bars labeled as GM + MS + LS give the sum of the changes simulated by GM, MS, and LS.

diagnose the poleward position of the winter Hadley cell.

The center panel of Fig. 9 shows the changes in the winter Hadley cell strength for the different simulations.
These new diagnostics support the previously shown results: the Hadley cells of GM weaken gently compared to $1 \mathrm{CO} 2$, whereas the Hadley cells of MS show stronger changes, similar to that of $\Delta \mathrm{SST}$ or $2 \mathrm{CO} 2$. The LS simulation induces weaker changes than MS with an opposite sign.

The upper panel of Fig. 9 summarizes the winter Hadley cell poleward expansion from our idealized simulations. The poleward expansions of experiments $2 \mathrm{CO} 2$ or $\Delta \mathrm{SST}$, when compared to $1 \mathrm{CO} 2$, are very close to that diagnosed from the IPSL-CM4 coupled model: they indicate a strong poleward expansion for the JJA winter cell, while the DJF winter cell is nearly unchanged. GM is quite similar to $2 \mathrm{CO} 2$ or $\triangle \mathrm{SST}$ in terms of poleward expansion, whereas MS and LS also show some poleward expansion, even if the expansion is weaker than that of GM. Our results confirm the previous conclusions established using more highly idealized GCM simulations. Frierson et al. (2007) also found a poleward expansion with increased mean temperature. Korty and Schneider (2008) and Walker and Schneider (2006) found a poleward expansion with a prescribed increased dry static stability. A smaller increase in width of the Hadley cells with increased meridional temperature gradient was also found by Korty and Schneider (2008), Walker and Schneider (2006), and Frierson et al. (2007).

According to Lu et al. (2008), the changes in the mean SST value modify the baroclinicity in subtropical regions as the baroclinicity changes due to stability were reported to be correlated with the Hadley cell expansion in global warming simulation or in the interannual variability due to ENSO. A uniform SST warming simulation shows a poleward expansion of the Hadley cells, whereas the meridional and longitudinal SST gradient change simulations only show a small expansion. The change of the SST gradients and their effects on midlatitude eddies appear to be of secondary importance in driving this poleward expansion. Our simulations support the possibility that dry static stability changes may be crucial for the poleward expansion of the Hadley cells.

The linearity parameter is indicated in Fig. 9 for the winter Hadley cell extent and strength changes. The sum of the Hadley circulation changes in GM, MS, and LS are similar to that induced in $\Delta$ SST. Thus, the different simulations GM, MS, and LS are complementary, and the effect of the different SST patterns is strongly linear.

\section{d. Zonal-mean velocity potential}

The changes in the Hadley circulation are often diagnosed with analysis of the mean meridional streamfunction, as in Mitas and Clement $(2005,2006)$ or in $\mathrm{Lu}$ 
DJF
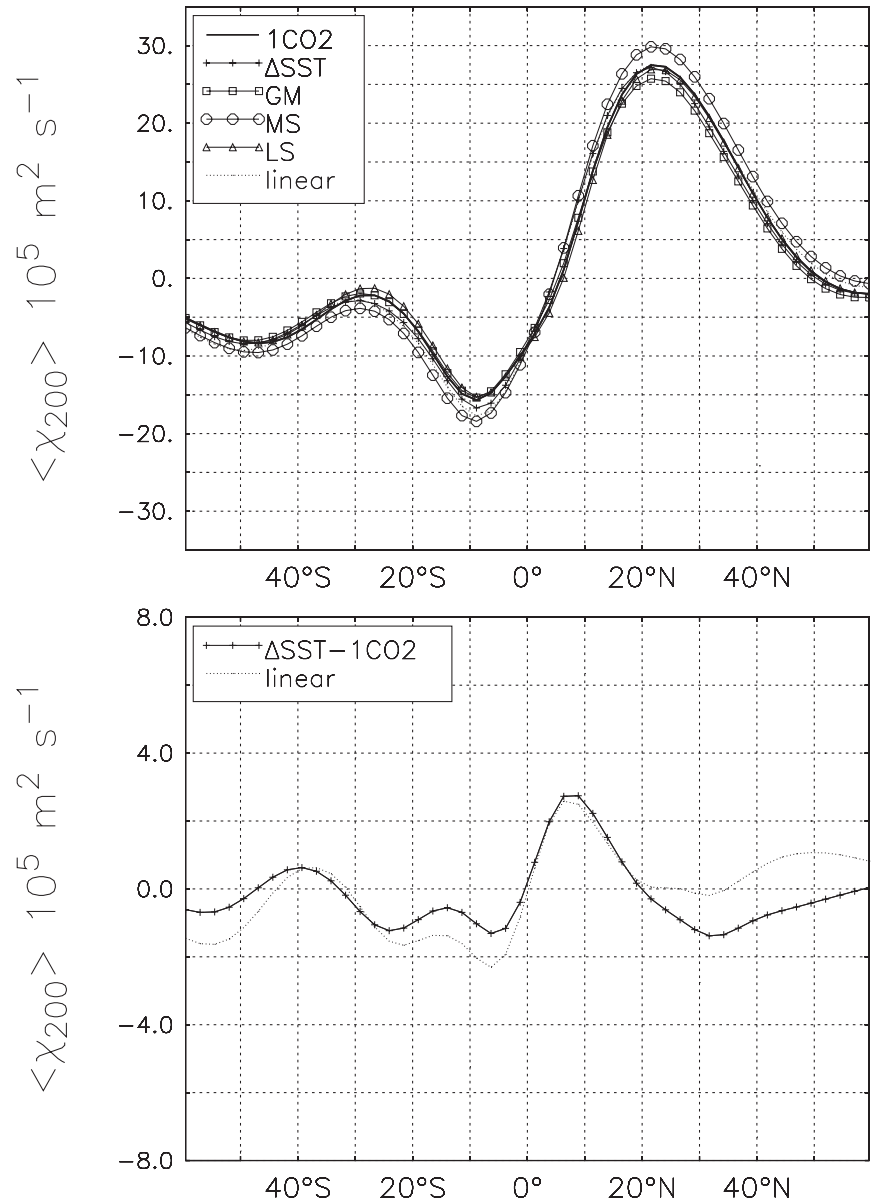

JJA
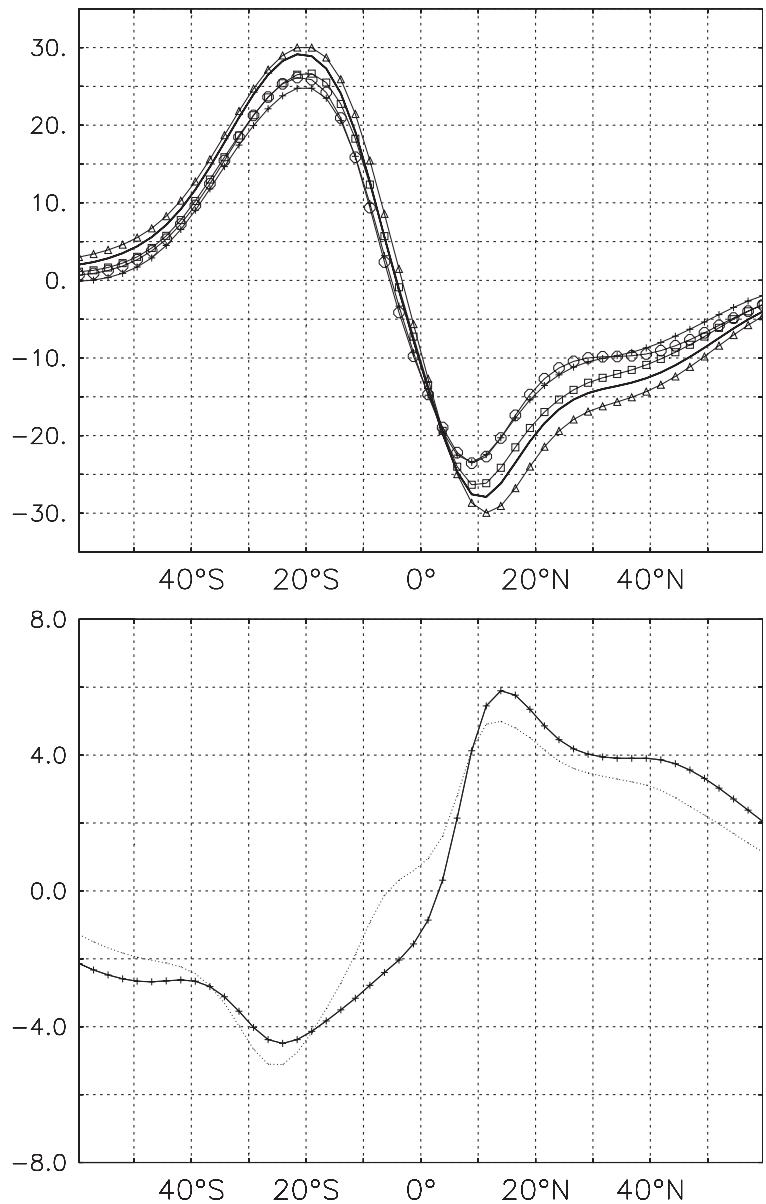

FIG. 10. Zonal-mean velocity potential at the 200-hPa height $\left\langle\chi_{200}\right\rangle$ for the different idealized simulations: (left) Northern Hemisphere winter (DJF) and (right) Southern Hemisphere winter (JJA). (top) The values for each simulation and (bottom) the differences of $\Delta$ SST with 1CO2, compared to the sum of the changes of GM, MS, and LS (labeled as linear).

et al. (2007, 2008). However, another diagnostic of the Hadley circulation intensity can be built with the velocity potential. The use of another diagnostic of the Hadley circulation provides a way to test the validity of the Hadley circulation changes diagnosed by the mean meridional streamfunction.

Following the methodology detailed in Tanaka et al. (2004), we assume that the Hadley circulation is adequately described by the zonal-mean velocity potential at the $200-\mathrm{hPa}$ height $\left\langle\chi_{200}\right\rangle$ where angle brackets indicate zonal averaging.

Figure 10 gives the zonal-mean velocity potential $\left\langle\chi_{200}\right\rangle$ for the boreal and austral winter in all the idealized simulations. The maximum of mass convergence (divergence) at the $200-\mathrm{hPa}$ level corresponds to positive (negative) value of $\left\langle\chi_{200}\right\rangle$ and occurs at $20^{\circ}$ in the winter hemisphere $\left(10^{\circ}\right.$ in the summer hemisphere) where the Hadley cell subsiding (ascending) branch is located. The Hadley cell ascending branch also indicates the zonal-mean location of the ITCZ. However, we can note that the actual location of the ITCZ varies strongly with longitude, especially in monsoon regions, as seen in Fig. 7.

In $\Delta$ SST, $\left\langle\chi_{200}\right\rangle$ shows stronger ascending motions located around $10^{\circ}$ in the summer hemisphere for DJF. On the other hand, for JJA, the ascents weaken over the Hadley cell ascending branch. Therefore, the DJF strengthening and the JJA weakening of the Hadley cells, found with the mean meridional streamfunction diagnostic, are confirmed.

To compare the different diagnostics of the Hadley circulation strength in a simple framework, an index of the Hadley cell strength is built as in Tanaka et al. (2004), using the maximum value of the zonal-mean 
velocity potential. We compute the peak value of the zonal-mean velocity potential, $\max \left\langle\chi_{200}\right\rangle$, which gives the intensity of the upper-tropospheric air convergence over the Hadley cell subsiding branch.

Figure 9 gives the Hadley circulation strength diagnosed using the velocity potential at 200-hPa height for the different idealized simulations. The results using velocity potentials are qualitatively consistent with the previous analysis of the Hadley circulation using streamfunctions. We note that the diagnosed changes of the Hadley cells using the velocity potential are consistently stronger than using the mean meridional streamfunction. As the tropopause is higher in the atmosphere in global warming conditions (Santer et al. 2003), part of the decrease of $\left\langle\chi_{200}\right\rangle$ may be attributed to changes in the level of detrainment, which rises at altitudes higher than 200 $\mathrm{hPa}$ in the tropics. However, we verified that the zonalmean velocity potential decreases at all heights in the upper troposphere and that the choice of the $200-\mathrm{hPa}$ level does not introduce biases in this analysis.

In $\triangle \mathrm{SST}$, the DJF strengthening and the JJA weakening of the Hadley cells, found with the mean meridional streamfunction diagnostic, are confirmed. In GM, both ascending and descending branches weaken; however, the weakening is smaller than that of $\Delta$ SST. MS changes are larger and are of the same order as the changes described by $\Delta$ SST. LS changes are also strong and correspond to changes opposite from $\Delta$ SST. The sum of the Hadley circulation changes obtained from the GM, MS, and LS idealized simulations are confirmed to account for the largest part of the changes induced by the full pattern of SST modifications.

\section{e. Zonal-mean rainfall}

Changes in the Hadley circulation should obviously impact the precipitation meridional structure. Figure 11 gives the zonal-mean precipitation changes of the different idealized simulations. The center panel shows the zonal-mean precipitation changes of $\Delta$ SST. The hydrological cycle increases globally with a southward shift of the ITCZ, especially in JJA. The contribution of the different components of the SST changes is then analyzed in the GM, MS, and LS simulations.

The hydrological cycle of GM increases, as already seen in Fig. 6. The increase of the zonal-mean precipitation field compared to $1 \mathrm{CO} 2$ is strikingly uniform. The hydrological cycle is more active as a result of the increase of the water vapor loading of the atmosphere following the "wet gets wetter and dry gets dryer" pattern described in Held and Soden (2006). As the zonal-mean meridional circulation changes are weak in GM (see Fig. 8), this effect is largely dominant.
In MS, the situation is very different: the Hadley circulation is more strongly modified and accounts for a large part of the changes in $\Delta$ SST, even if the mean SST value is unchanged. The intensity of the hydrological cycle is consistently weakly modified but the locations of the precipitations are affected. In DJF and JJA, the zonal-mean position of the ITCZ and the Hadley cells' ascending branch shift southward, as shown by the increase of precipitation from $5^{\circ} \mathrm{N}$ to $20^{\circ} \mathrm{S}$.

The longitudinal SST changes, whose effects are investigated in LS, also have a significant effect and induce a northward shift of the ITCZ for JJA, while the changes are weaker for DJF. We had shown that the Hadley cell strength changes are opposite from $\Delta$ SST and consistently find that the precipitation changes are also opposite. Again, the longitudinal anomalies act to damp the modifications owing to the SST meridional anomalies.

The "linear" changes of the rainfall, that is, the sum of the precipitation changes of GM, MS, and LS, are similar compared to those of $\Delta$ SST. Therefore, the changes are linear, and our simulations are able to provide a linear decomposition of the zonal-mean precipitation changes induced by the SST changes in the global warming experiments of the IPSL-CM4 coupled model.

Even if the most robust signal of the hydrological cycle is caused by the global mean SST warming, some zonalmean displacement of the large-scale ascent are caused by the SST meridional and longitudinal gradient changes, which shift the zonal-mean ITCZ position.

\section{f. Walker circulation}

Some changes in the Walker circulation are expected from the Hadley circulation changes. During ENSO episodes, previous studies found that a weakening of the Walker cells was correlated with a strengthening (weakening) of the Northern (Southern) Hemisphere Hadley cell. Furthermore, the Walker circulation in global warming conditions was shown to be strongly affected in the coupled model scenario simulation of global warming (Vecchi and Soden 2007), whereas the Hadley circulation was shown to weaken more gently (Mitas and Clement 2006; Gastineau et al. 2008).

We need a synthetic parameter to describe the response of the Walker circulation to SST changes. Various measures have been proposed to assess the strength of the Walker circulation: Tanaka et al. (2004) used the yearly mean deviations of the $200-\mathrm{hPa}$ velocity potential from the zonal-mean field, whereas Zhang and Song (2006) and Vecchi and Soden (2007) used the sea level pressure (SLP). However, the yearly mean deviations of the velocity potential from the zonal-mean field diagnose longitudinal variation of the Hadley cell together 
DJF
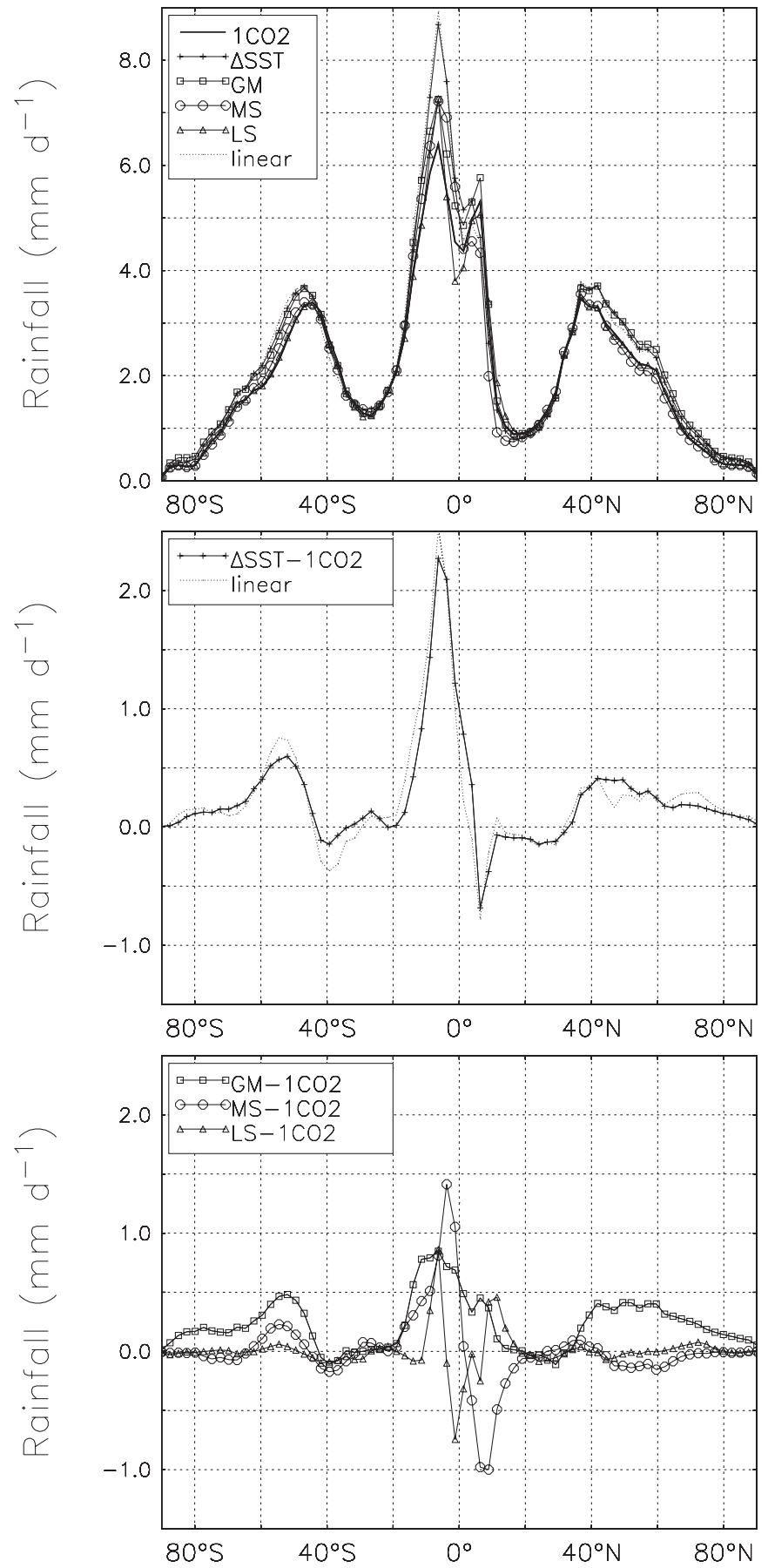

JJA
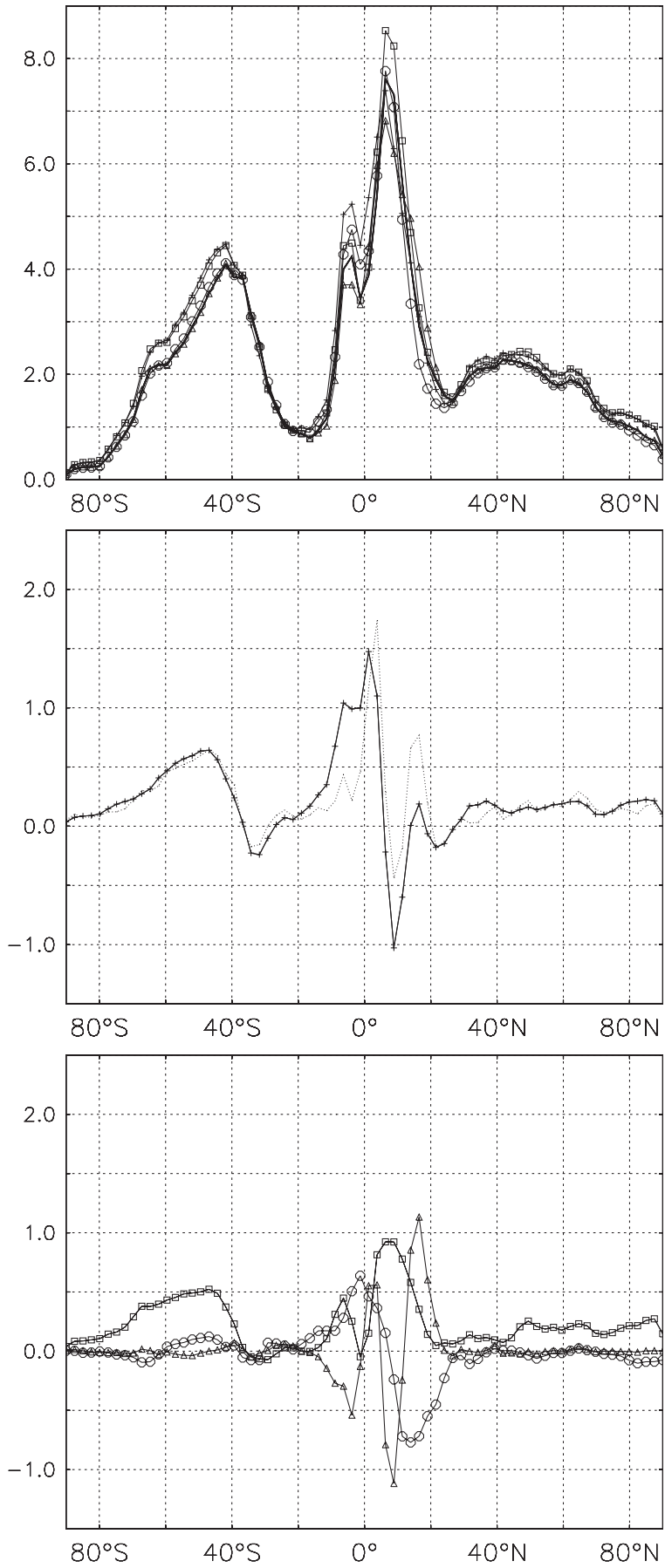

FIG. 11. Zonal-mean precipitation $\left(\mathrm{mm} \mathrm{day}^{-1}\right.$ ) for the different idealized simulations: (left) Northern Hemisphere winter (DJF) and (right) Southern Hemisphere winter (JJA). (top) Values for each simulation; (middle) differences of $\Delta$ SST with 1CO2, compared to the sum of the changes of GM, MS, and LS (labeled as linear); and (bottom) the individual changes of GM, MS, and LS. 
with Walker circulation cells. Furthermore, the use of SLP is useful to compare model with observations, but the SLP is not a direct measure of the atmospheric circulation.

Therefore, in this study, we build another index of the Walker circulation strength. We use the yearly mean 200-hPa velocity potential averaged over the tropical region to diagnose the changes at all the longitudes. The tropics are defined by the boundaries of the Hadley circulation presented in section $3 \mathrm{c}$. The tropical meridional mean of the $200-\mathrm{hPa}$ velocity potential is computed as

$$
\left[\chi_{200}\right](\lambda)=\int_{\phi_{S}}^{\phi_{N}} \chi_{200}(\lambda, \phi) \cos \phi d \phi
$$

where $\phi_{N}$ and $\phi_{S}$ are the northern and southern extratropical boundaries of the Hadley cells. The square brackets indicate the meridional tropical averaging. We can check that the tropical mean velocity potential at $200 \mathrm{hPa}$, defined over the Hadley circulation region, is on the order of $0.510^{5} \mathrm{~m}^{2} \mathrm{~s}^{-1}$ so that the atmospheric Walker circulation diagnosed in this way is reasonably closed in the tropical region.

Figure 12 gives the tropical meridional mean of the velocity potential for the idealized simulations, in yearly mean. The strongest ascending motions correspond to negative $\left[\chi_{200}\right]$ and occur over the Pacific warm pool region. Secondary large-scale ascents are located over the American and African continents, which correspond to local minima of $\left[\chi_{200}\right]$. Large-scale subsiding motions (positive velocity potential) occur mainly over the Atlantic, western Indian, and eastern Pacific Oceans: these regions are marked by local maxima of $\left[\chi_{200}\right]$.

To assess the regional strength of the Walker circulation in a simple framework, the longitudinal extrema of $\left[\chi_{200}\right]$ are studied. The strength of the Walker circulation cells are diagnosed by the peak-to-peak amplitude of the meridional-mean $200-\mathrm{hPa}$ velocity potential, $\operatorname{pk}-\operatorname{pk}\left[\chi_{200}\right]$. It corresponds to the difference between a local maximum and the closest local minimum. The intensity of six Walker circulation cells is diagnosed in this way. Figure 13 gives the strength of each of the Walker circulation cells and their changes when compared to $1 \mathrm{CO} 2$.

The Walker circulation in $\Delta$ SST mainly weakens where the ascents are the strongest (i.e., over the Indian Ocean and the warm pool region). The upper-tropospheric motions also weaken over the Atlantic Ocean, the American continent, and the African continent. However, the subsident motions are diagnosed to increase over the eastern Pacific. Vecchi and Soden (2007) show
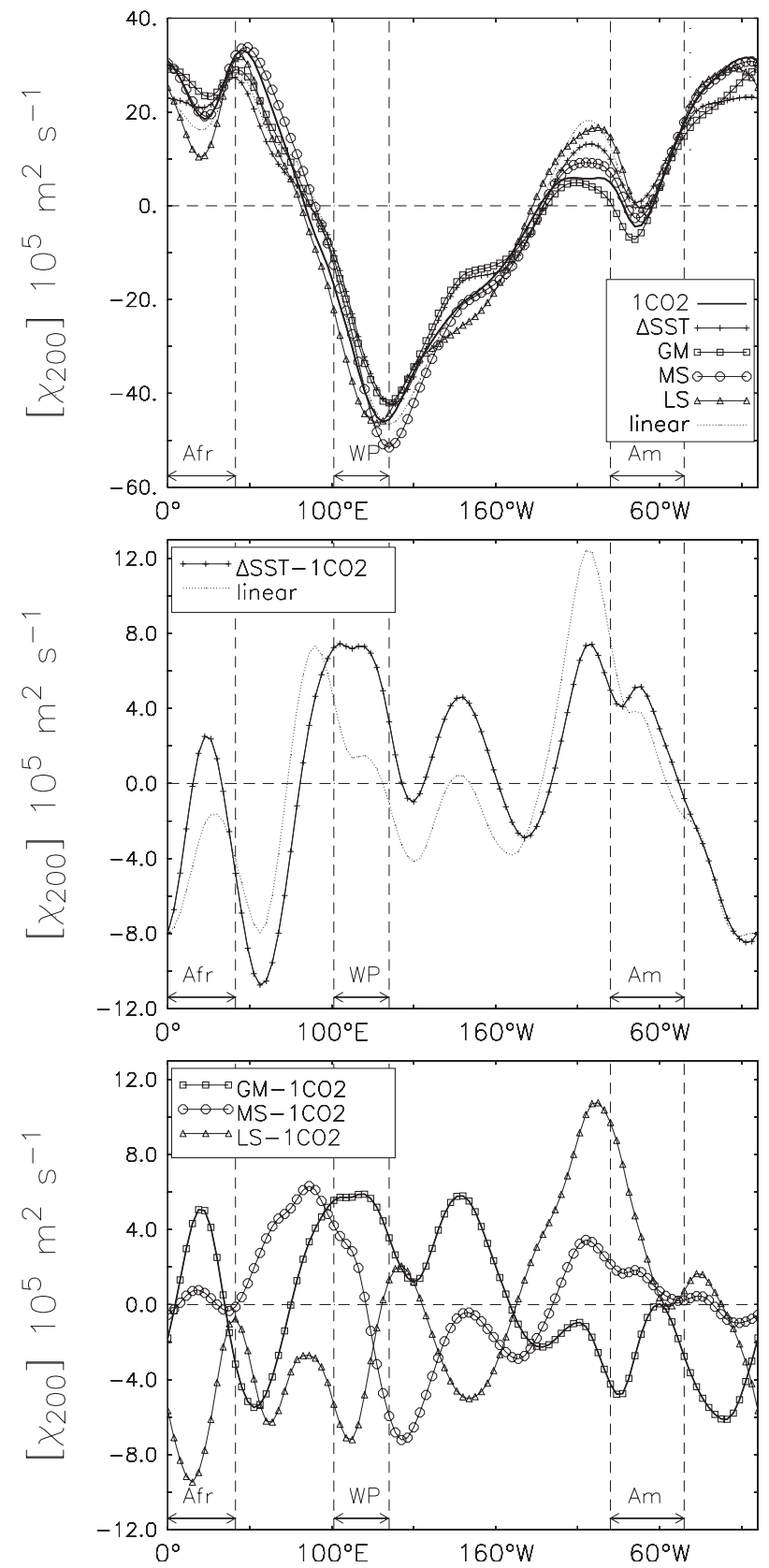

FIG. 12. Tropical meridional mean of the velocity potential at the 200-hPa height $\chi_{200}$ for the different idealized simulations. (top) Values for each simulations; (middle) differences of $\triangle \mathrm{SST}$ with $1 \mathrm{CO} 2$, compared to the sum of the changes of GM, MS, and LS (labeled as linear); and (bottom) the individual changes of GM, MS, and LS. The locations of the main continents are labeled Afr: Africa, WP: warm pool (or Maritime Continent), and Am: America. The results are from yearly means.

that the Walker circulation of the multimodel mean mostly weakens over the Pacific Ocean. Therefore, in IPSL-CM4, the Walker circulation changes are different from the multimodel mean. 


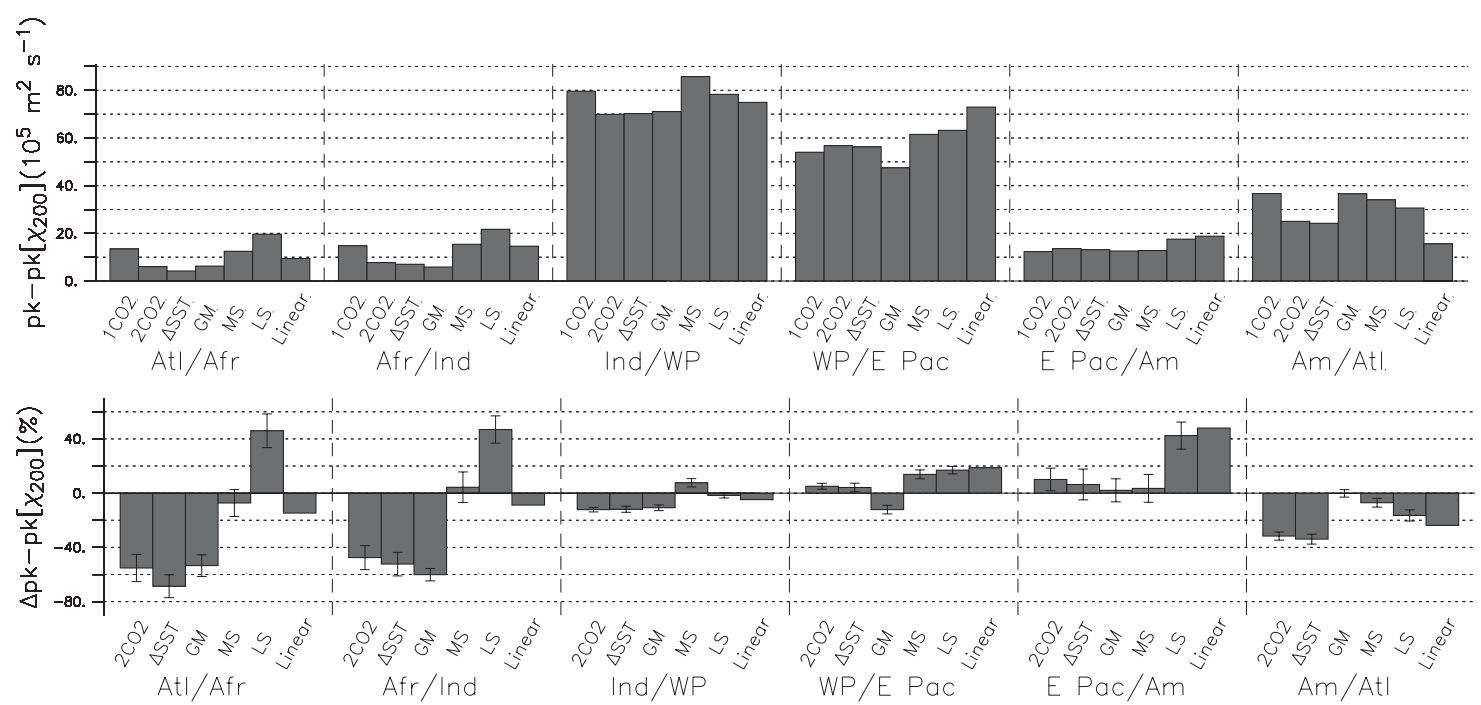

FIG. 13. (top) Walker circulation strength, given by the peak-to-peak amplitude of the 200-hPa velocity potential tropical meridional mean $\left(\chi_{200}\right)$ for the simulations $1 \mathrm{CO} 2,2 \mathrm{CO} 2$, GM, MS, and LS. (bottom) The relative changes between the 2CO2, GM, MS, and LS simulations when compared to the control simulation 1CO2. The relative variations are in percent. A positive value indicates a strengthening; a negative value a weakening. The bar labeled linear gives the changes of the sum of the simulations GM, MS, and LS. Errors bars indicate the $95 \%$ confidence level intervals using $t$ statistics, assuming that each 1-yr ensemble member is normally distributed. Labels correspond to the Walker circulation cell regions Atl/Afr: Atlantic Ocean/Africa, Afr/Ind: Africa/Indian Ocean, Ind/WP: Indian Ocean/warm pool, WP/EPac: warm pool/eastern Pacific Ocean, EPac/Am: eastern Pacific Ocean/America, and Am/Atl: America/Atlantic Ocean.

In GM, the Walker circulation weakens everywhere except over America where the changes are insignificant. In this simulation, the Walker circulation also weakens over the eastern Pacific Ocean. MS and LS show changes in Walker circulation very different from $\Delta$ SST or GM. In MS the Walker circulation increases where the zonal circulation is strong, over the Indian and Pacific Oceans, whereas the Walker circulation is hardly modified over the other regions. LS also shows a strengthening of the Walker circulation, but the strengthening is located in almost all regions.

We note that the Walker circulation changes are only weakly linear, especially over the regions where the Walker circulation intensity is small. Therefore, some nonlinearities between the changes of GM, MS, and LS may also account for the change of $\Delta$ SST.

In the coupled model, IPSL-CM4, the main Walker circulation changes are thus induced by the mean SST warming that decreases the large-scale tropical circulation, as is expected from the global weakening of the large-scale circulation. Nevertheless, part of the Walker circulation changes depend more on the asymmetric warming between the Atlantic and Pacific Oceans, which strengthens the Walker cells. Another part of the changes comes from the meridional SST gradients that also act to strengthen the Walker circulation. Finally, nonlinearities are also important, and we suggest that the land- covered surface may amplify or dump the Walker circulation changes.

\section{g. Longitudinal structure of the Hadley circulation}

In Fig. 4, the meridional SST gradients of simulation LS were demonstrated to change differently over the main oceanic basins. These changes may force the meridional circulation differently over each oceanic basin, and the relatively small changes in the zonal-mean Hadley circulation may arise from the cancellation between much larger but opposite changes. Therefore, the meridional atmospheric overturning circulation was diagnosed over each ocean basin using meridional streamfunctions. Three oceanic basins are defined by three longitudinal bands that cover the surface of the earth: $70^{\circ} \mathrm{W}-25^{\circ} \mathrm{E}$ for the Atlantic Ocean, $25^{\circ}-125^{\circ} \mathrm{E}$ for the Indian Ocean, and $125^{\circ} \mathrm{E}-70^{\circ} \mathrm{W}$ for the Pacific Ocean. The three longitudinal bands are illustrated in Fig. 5. To ensure that the meridional streamfunction diagnoses a closed mass circulation and to exclude any influence from the zonal circulation, we remove the mass-weighted vertical mean value from the actual value of the meridional velocity when zonally averaged over the three longitudinal bands.

Figure 14 shows the meridional streamfunction obtained over each oceanic basin for the Northern and Southern Hemisphere winter. We note that the sum of 
DJF
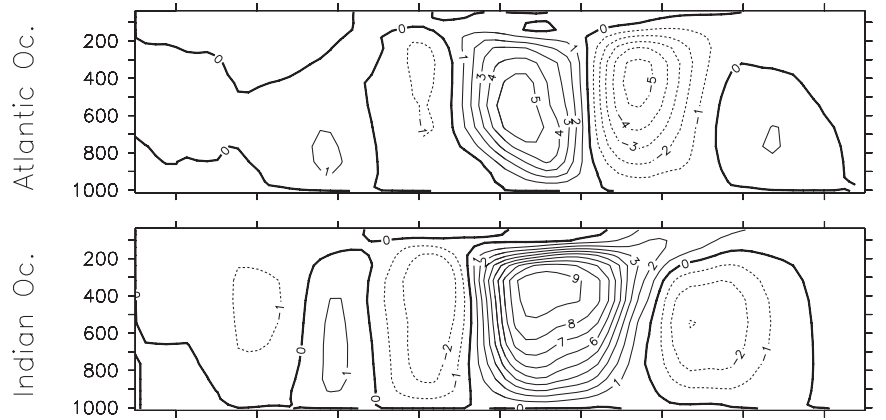

$\dot{0}$
0
.$\frac{U}{U}$
0
0
0

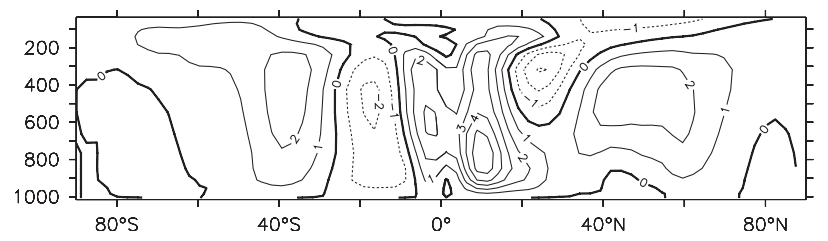

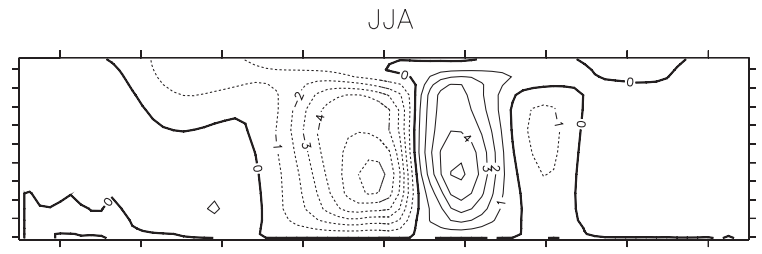

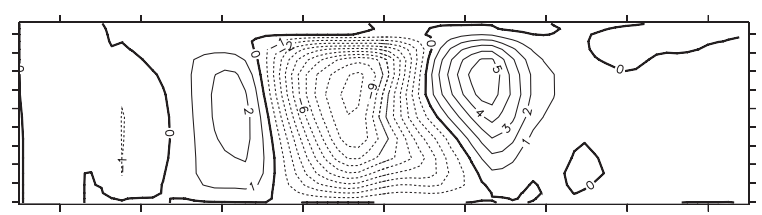

FIG. 14. Meridional streamfunction for the control simulation $1 \mathrm{CO} 2$ : longitudinal band located over the (top) Atlantic $\left(70^{\circ} \mathrm{W}-25^{\circ} \mathrm{E}\right)$, (middle) Indian $\left(25^{\circ}-125^{\circ} \mathrm{E}\right)$, and (bottom) Pacific $\left(125^{\circ} \mathrm{E}-70^{\circ} \mathrm{W}\right)$ Ocean for (left) boreal (DJF) and (right) austral (JJA) winters. Contour interval is $1 \times 10^{10} \mathrm{~kg} \mathrm{~s}^{-1}$.

the streamfunctions representing the three basins is equal to the zonal-mean meridional streamfunction shown in Fig. 8. The meridional streamfunction reveals that the meridional circulation is strong over the Indian Ocean due to the Asiatic and Australian monsoons. It is rather weak over the Pacific Ocean, especially during Northern Hemisphere winter DJF, though it represents a large band of longitude, as the Walker component of the atmospheric circulation is more important over this region.

To quantify the intensity of the winter Hadley cells over each basin, the maxima of the meridional streamfunction absolute value, averaged between the 400- and 700-hPa levels, are computed as a measure of the winter Hadley cell strength. Figure 15 gives the changes of the meridional mass circulation strength diagnosed over the three longitudinal bands. The changes in $2 \mathrm{CO} 2$ or $\triangle \mathrm{SST}$ are quite similar: the meridional circulation weakens over all basins, except over the Pacific Ocean for DJF where a strong increase is found. A difference between $2 \mathrm{CO} 2$ and $\triangle \mathrm{SST}$ is noted for DJF over the Indian Ocean. As the Indian Ocean longitude band is covered by land over the Northern Hemisphere, we suggest that snow and sea ice albedo feedbacks are important in $2 \mathrm{CO} 2$, whereas these processes are not accounted for in $\triangle \mathrm{SST}$, since this simulation does not include any sea ice change.

The Hadley cells do not decrease uniformly in all basins in the simulation GM, but the decrease is located over the Atlantic Ocean and over the Indian Ocean for JJA, while a strengthening occurs in the Pacific Ocean. Thus, the zonal-mean circulation weakening in GM is more complex than a uniform decrease of the circula- tion everywhere. The uniform SST warming mostly weakens the Walker circulation over the Pacific Ocean, whereas it weakens the meridional circulation over the Atlantic and Indian Oceans.

For MS, the meridional circulation over the Indian and Pacific Oceans intensifies in DJF, whereas it weakens for JJA. It corresponds to the strengthening of the SST gradient in the Northern Hemisphere for DJF and a weakening in the Southern Hemisphere for JJA, as shown in Fig. 4.

In LS, the Hadley cell weakens in DJF and strengthens in JJA for both the Pacific and the Indian Ocean. Over the Atlantic Ocean, the Hadley cells strengthen in both seasons. The changes over the Indian and Pacific Oceans are associated with the decrease or increase of the meridional SST gradient over the winter Hadley cell region for DJF or JJA, respectively (see Fig. 4). Over the Atlantic Ocean the strengthening observed in DJF corresponds well with the meridional SST increase over the Northern Hemisphere tropics, but the strengthening for JJA is not consistent with the decrease of the meridional SST changes. The JJA changes over the Atlantic Ocean may be forced by the remote influence of the Asiatic monsoon that is mostly affected by the Indian Ocean SST gradients.

Finally, the changes over each basin appear to be only weakly linear, as the sum of the changes of GM, MS, and LS is quite different from the $\Delta$ SST simulation. The nonlinearities are the strongest over the Indian and Atlantic Oceans, where land surfaces are expected to feed back on the atmospheric circulation and therefore 

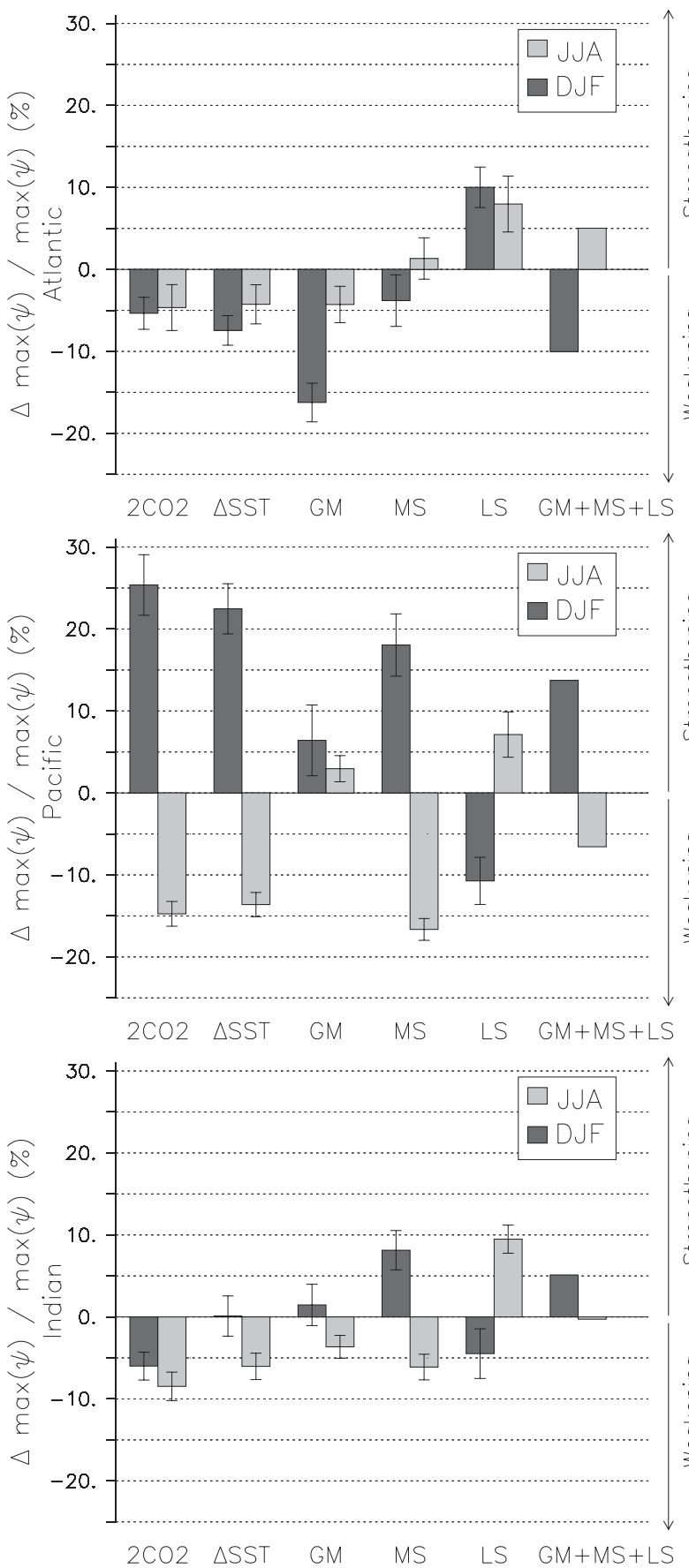

FIG. 15. Changes in the meridional circulation in the idealized simulations, given by the relative changes of the maximum absolute value of the meridional streamfunction, averaged between the 400- and 700-hPa levels over the three longitudinal bands corresponding to the Indian $\left(25^{\circ}-125^{\circ} \mathrm{E}\right)$, Atlantic $\left(70^{\circ} \mathrm{W}-25^{\circ} \mathrm{E}\right)$, and Pacific $\left(125^{\circ} \mathrm{E}-70^{\circ} \mathrm{W}\right)$ Oceans. Errors bars indicate the $95 \%$ confidence level intervals using $t$ statistics, assuming that each 1 -yr ensemble member is normally distributed. generate nonlinearities. As a consequence, our simulations appear inadequate to describe regional changes, especially over land surfaces. But, overall, these nonlinearities cancel each other in the global and zonalmean changes.

\section{Discussion and conclusions}

Ensemble simulations using the atmospheric component of the coupled model IPSL-CM4, that is, the atmospheric GCM LMDZ4, have been used to investigate the effect of SST changes associated with double $\mathrm{CO}_{2}$ concentration on large-scale tropical circulation and precipitation. The atmospheric GCM was forced by prescribed SST from the coupled model IPSL-CM4 and was able to mimic the results of the coupled model in the tropical regions.

To validate the methodology of the present experiments, we first demonstrated that the robust modifications of the tropical climate, which are characteristic of global warming and affect such key parameters as tropical precipitation or dry static stability, can be represented using the SST as the only modified boundary condition while keeping the sea ice and greenhouse gas concentration constant. Then, the impact of some specific properties of modified SST patterns on the tropical climate is studied. The SST change of IPSL-CM4 is divided into a uniform, a meridional, and a longitudinal component. The consequences, in terms of precipitation and large-scale circulation, for each of those SST components are studied separately.

The experiment GM uses a uniform SST warming as a boundary condition without any SST latitudinal or longitudinal gradient changes. In GM, the dry static stability increases and, as a result, the whole tropical circulation slows down, while the hydrological cycle is stronger. The weakening of the large-scale circulation is diagnosed in the Hadley circulation over the Atlantic Ocean during DJF and the Indian Ocean during JJA. The Walker circulation over the Pacific Ocean also weakens. Moreover, the poleward expansion of the winter hemisphere Hadley cell is well captured by GM, and we suggest that the effects resulting from the changes in the dry static stability and tropopause height are potentially important in driving the expansion.

MS uses the meridional component of the SST changes with the uniform mean change kept equal to zero. As the mean tropical temperature changes are weak, the rainfall and dry static stability changes are correspondingly weak. This simulation lacks some of the main mechanisms reviewed by Held and Soden (2006) to explain the main changes in the hydrological cycle associated with global warming. On the other hand, as the 
changes in the meridional gradient of SST are accounted for in MS, the variations in the Hadley circulation strength shown by IPSL-CM4 in double $\mathrm{CO}_{2}$ conditions are surprisingly well simulated. As a consequence the zonal-mean meridional ITCZ shifts are also fairly well represented. These results clearly demonstrate that the meridional structure of the SST, that is, the changes in its meridional gradients distinguished from the mean global changes, are crucial to assess Hadley circulation changes in terms of strength as well as its consequences over the ITCZ zonal-mean structure. Very little poleward expansion of the winter Hadley cells is diagnosed in MS, which indicates that the changes of the meridional SST gradients and their effect on midlatitude eddy activity are not the main modulators of the Hadley cell poleward expansion. The major role of the SST gradient on the Hadley cell strength was largely expected from the idealized GCM study of Walker and Schneider $(2006,2005)$. These authors suggest that the Hadley cells are strongly dependent on extratropical climate as the eddy momentum flux strongly influences the strength of the Hadley cells in idealized GCM simulations. However, Walker and Schneider (2006) found that increased static stability would, on the contrary, increase the Hadley cell strength. We suggest that moist processes, which are missing in dry GCM simulations, may be crucial to simulate the decrease of the Hadley cell in global warming conditions.

LS uses only the SST longitudinal anomalies of the IPSL-CM4 double $\mathrm{CO}_{2}$ simulation. Rind and Perlwitz (2004) noted that longitudinal circulation could divert energy from the meridional cells. The modification of the Hadley circulation during ENSO also provides a good example of modification of the large-scale circulation by longitudinal anomalies (Wang 2004). One might think that El Niño-like changes over the Pacific Ocean would appear as a major signal in the longitudinal change of SST. However, in our simulations, the major longitudinal changes of SST follow a pattern that creates a distinction between the Atlantic and Pacific Oceans. In particular, the important slowdown of the thermohaline circulation in the coupled model IPSLCM4 strongly modifies the SST warming in the Atlantic Ocean. Therefore, the changes of the tropical largescale circulation driven by the longitudinal SST anomalies in LS are different from the modification caused by ENSO. In LS, the Walker circulation strengthens and the Hadley cell strength is modified with an effect opposite to that of $\Delta$ SST. Therefore, longitudinal SST anomalies exert a negative feedback on the changes associated with modifications of the zonal-mean meridional SST gradients. Moreover, we show that the longitudinal anomalies are important for the simulation of the Walker circulation changes over the eastern $\mathrm{Pa}$ cific Ocean, American continent, and Atlantic Ocean, where a northward shift of the ITCZ is diagnosed.

Our results therefore indicate that a uniform SST warming, such as in the $+2-\mathrm{K}$ experiments pioneered by Cess and Potter (1988), is quite useful to provide insight into some of the most robust mechanisms affecting the coupled models in conditions of global warming. Indeed, some circulation changes shown by our uniform warming simulation have many similarities with the corresponding changes of the multimodel mean in double $\mathrm{CO}_{2}$ conditions: the Hadley circulation gently weakens, similar to the finding of Gastineau et al. (2008) using a multimodel mean, and the Walker circulation weakens strongly over the Pacific Ocean, similar to the findings of Vecchi and Soden (2007). However, uniform SST warming simulations turn out to be unable to mimic the modifications of the Hadley cell strength as well as the zonal-mean precipitation structure. In our simulations, the zonalmean meridional gradients of the SST are the main modulators of the Hadley circulation strength, as found by Rind and Perlwitz (2004). As the changes in the meridional SST gradients among existing coupled models are not characterized by a good overall agreement, this result provides an explanation to the also very weak agreement of these coupled simulations in terms of Hadley circulation changes (Gastineau et al. 2008).

The longitudinal changes are of secondary importance in modifying the Hadley cells. Nevertheless, we show that the asymmetry between the Atlantic Ocean and the other oceanic basins strengthens the Walker circulation in most regions and has a small but significant impact on the Hadley cell strength. However, the longitudinal changes in IPSL-CM4, with our SST decomposition, are more strongly dependent on the slowdown of the Atlantic thermohaline circulation than on an El Niño-like pattern. As the uncertainties on the modifications of both the thermohaline and El Niño circulations are also very large in existing coupled model simulations, the longitudinal SST warming pattern is also believed to be quite model dependent.

In this paper, we provide a consistent methodology to test the impact of different SST changes on the largescale atmospheric circulation and precipitation in the tropics. Some of the most robust features of global warming emphasized by the last IPCC AR 4 experiments, such as the mean weakening of the large-scale circulation or the Hadley cell poleward expansion, are, in fact, the results of the only uniform component of the warming. On the other hand, the strong changes induced by the changes in the meridional SST gradient, or the weaker changes resulting from longitudinal SST changes, may deeply modify the prediction of rainfall changes and 
probably explain why the hydrological consequences of anthropogenic climate changes are still so difficult to predict.

Acknowledgments. We acknowledge the Institut PierreSimon Laplace (IPSL) modeling group in making the CMIP3 simulations available. The simulations in this work were performed at the Institut du Développement et des Ressources en Informatique Scientifique (IDRIS), which also provided technical support to this work.

\section{REFERENCES}

Allen, R. A., and W. J. Ingram, 2002: Constraints on future changes in climate and the hydrologic cycle. Nature, 419, 224-232.

Betts, A. K., 1998: Climate-convection feedbacks: Some further issues. Climatic Change, 39, 35-38.

—- and W. Ridgway, 1988: Coupling of the radiative, convective, and surface fluxes over the equatorial Pacific. J. Atmos. Sci. 45, 522-536.

—, and —-1989: Climatic equilibrium of the atmospheric convective boundary layer over a tropical ocean. J. Atmos. Sci., 46, 2621-2641.

Bony, S., and K. A. Emanuel, 2001: A parameterization of the cloudiness associated with cumulus convection; evaluation using TOGA COARE data. J. Atmos. Sci., 58, 3158-3183.

Cess, R. D., and G. L. Potter, 1988: A methodology for understanding and intercomparing atmospheric climate feedback processes in general circulation models. J. Geophys. Res., 93, 8305-8314.

Emanuel, K. A., 1993: A cumulus representation based on the episodic mixing model: The importance of mixing and microphysics in predicting humidity. The Representation of $\mathrm{Cu}$ mulus Convection in Numerical Models of the Atmosphere, Meteor. Monogr., No. 46, Amer. Meteor. Soc., 185-192.

Frierson, D. M. W., J. Lu, and G. Chen, 2007: Width of the Hadley cell in simple and comprehensive general circulation models. Geophys. Res. Lett., 34, L18804, doi:10.1029/2007GL031115.

Gastineau, G., H. Le Treut, and L. Li, 2008: Hadley circulation changes under global warming conditions indicated by coupled climate models. Tellus, 60A, 863-884.

Held, I. M., and B. J. Soden, 2006: Robust responses of the hydrological cycle to global warming. J. Climate, 19, 5686-5699.

Hourdin, F., and Coauthors, 2006: The LMDZ4 general circulation model: Climate performance and sensitivity to parameterized physics with emphasis on tropical convection. Climate Dyn., 27, 787-813.

$\mathrm{Hu}$, Y., and Q. Fu, 2007: Observed poleward expansion of the Hadley circulation since 1979. Atmos. Chem. Phys., 7, 5229-5236.

Knutson, T., and S. Manabe, 1995: Time-mean response over the tropical pacific to increased $\mathrm{CO}_{2}$ in a coupled oceanatmosphere model. J. Climate, 8, 2181-2199.

Korty, R. L., and T. Schneider, 2008: Extent of Hadley circulations in dry atmospheres. Geophys. Res. Lett., 35, L23803, doi:10.1029/ 2008 GL035847.

Krinner, G., and Coauthors, 2005: A dynamic global vegetation model for studies of the coupled atmosphere-biosphere system. Global Biogeochem. Cycles, 19, GB1015, doi:10.1029/ 2003 GB002199.

Li, Z., 2006: Atmospheric GCM response to an idealized anomaly of the Mediterranean sea surface temperature. Climate Dyn., 27, 543-552.
Liu, Z., S. Vavrus, F. He, N. Wen, and Y. Zhong, 2005: Rethinking tropical ocean response to global warming: The enhanced equatorial warming. J. Climate, 18, 4684-4700.

Lu, J., G. A. Vecchi, and T. Reichler, 2007: Expansion of the Hadley cell under global warming. Geophys. Res. Lett., 34, L06805, doi:10.1029/2006GL028443.

—, G. Chen, and D. M. W. Frierson, 2008: Response of the zonal-mean atmospheric circulation to El Niño versus global warming. J. Climate, 21, 5835-5851.

Mitas, C. M., and A. Clement, 2005: Has the Hadley cell been strengthening in recent decades? Geophys. Res. Lett., 32, L03809, doi:10.1029/2004GL021765.

— and - 2006: Recent behavior of the Hadley cell and tropical thermodynamics in climate models and reanalyses. Geophys. Res. Lett., 33, L01810, doi:10.1029/2005GL024406.

Moritz, R. E., C. M. Bitz, and E. J. Steig, 2002: Dynamics of recent climate change in the Arctic. Science, 297, 1497-1502.

Rind, D., and J. Perlwitz, 2004: The response of the Hadley circulation to climate changes, past and future. The Hadley Circulation: Past, Present and Future, H. F. Diaz and R. S. Bradley, Eds., Advances in Global Change Research, Vol. 21, Kluwer Academic Publishers, 399-435.

Russell, J. L., R. Stouffer, and K. Dixon, 2006: Intercomparison of the Southern Ocean circulations in IPCC coupled model control simulations. J. Climate, 19, 4560-4575.

Santer, B. D., and Coauthors, 2003: Behavior of tropopause height and atmospheric temperature in models, reanalyses, and observations: Decadal changes. J. Geophys. Res., 108, 4002, doi:10.1029/2002JD002258.

Sugi, M., A. Noda, and N. Sato, 2002: Influence of the global warming on tropical cyclone climatology: An experiment with the JMA global model. J. Meteor. Soc. Japan, 80, 249-272.

Swingedouw, D., P. Braconnot, and O. Marti, 2006: Sensitivity of the Atlantic meridional overturning circulation to the melting from northern glaciers in climate change experiments. Geophys. Res. Lett., 33, L07711, doi:10.1029/2006GL025765.

Tanaka, H. L., N. Ishizki, and A. Kitoh, 2004: Trend and interannual variability of Walker, monsoon and Hadley circulation defined by velocity potential in the upper troposphere. Tellus, 56A, 250-269.

Vecchi, G. A., and B. J. Soden, 2007: Global warming and the weakening of the tropical circulation. J. Climate, 20, 4316-4340.

Waliser, D. E., Z. Shi, J. R. Lanzante, and A. H. Oort, 1999: The Hadley circulation: Assessing NCEP/NCAR reanalysis and sparse in-situ estimates. Climate Dyn., 15, 719-735.

Walker, C. C., and T. Schneider, 2005: Response of idealised Hadley circulations to seasonally varying heating. Geophys. Res. Lett., 32, L06813, doi:10.1029/2004GL022304.

—, and —, 2006: Eddy influences on Hadley circulations: Simulations with an idealized GCM. J. Atmos. Sci., 63, $3333-3350$.

Wang, C., 2004: ENSO, Atlantic climate variability, and the Walker and Hadley circulations. The Hadley Circulation: Past, Present and Future, H. F. Diaz and R. S. Bradley, Eds., Advances in Global Change Research, Vol. 21, Kluwer Academic Publishers, 85-120.

Xu, K.-M., and K. A. Emanuel, 1989: Is the tropical atmosphere conditionally unstable? Mon. Wea. Rev., 117, 1471-1479.

Zhang, M., and H. Song, 2006: Evidence of deceleration of atmospheric vertical overturning circulation over the tropical Pacific. Geophys. Res. Lett., 33, L12701, doi:10.1029/2006GL025942. 